
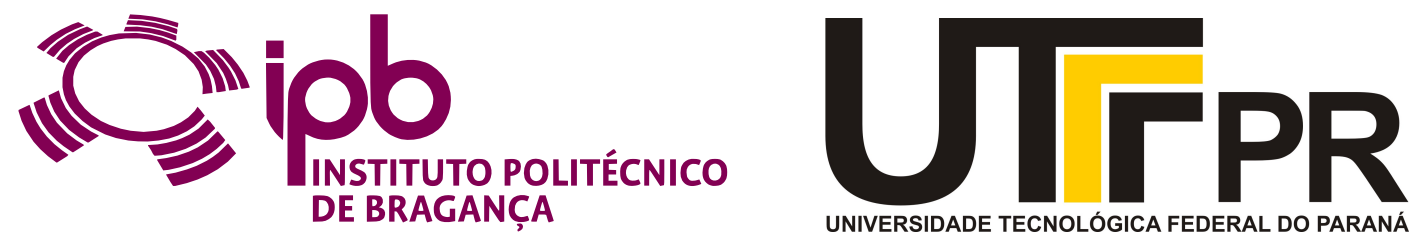

\title{
Environmental performance assessment of the transport sector in the European Union
}

\section{SARAh Beatriz Gruetzmacher}

\author{
Supervised by \\ Prof. Dr. Clara Vaz \\ Prof. Dr. Ângela Ferreira \\ Prof. Me. Annemarlen Gehrke Castagna
}




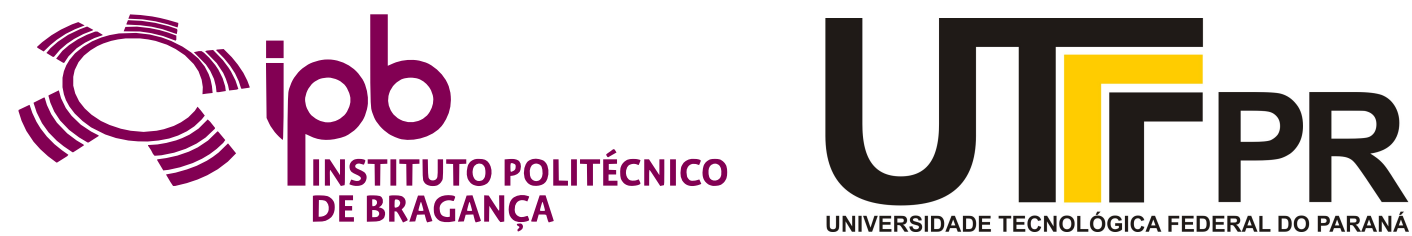

\title{
Environmental performance assessment of the transport sector in the European Union
}

\author{
SARAH BeAtriz Gruetzmacher
}

Thesis presented in the School of Technology and Management of the Polytechnic Institute of Bragança to fulfill the requirements of a Master of Science Degree in Industrial Engineering (Electrical Engineering branch).

\author{
Supervised by \\ Prof. Dr. Clara Vaz \\ Prof. Dr. Ângela Ferreira
}

Prof. Me. Annemarlen Gehrke Castagna 



\section{Acknowledgments}

First of all, I would like to thank my parents, Paulo and Roselene, for their constant support during my search for this opportunity to study abroad.

To my supervisors, Prof. Dr. Ângela Ferreira and Prof. Dr. Clara Vaz, for all the knowledge, support, encouragement and patience transmitted during the execution of this work

To Prof. Dr. Victor Frencl for the encouragement given during the beginning of this process and for all the knowledge shared when we worked together. Everything I learned was of great importance for the accomplishment of this work.

To my sister Bruna and to Alice Fey, Karine Verbicaro, Liege Aguiar, Pedro Humberto Nunes, Rodolpho Fagundes, Victor Avila and all the friends who helped and supported me in some way during the development of this work.

Finally, I would like to thank the Universidade Tecnológica Federal do Paraná (UTFPR) Campus Curitiba and the Instituto Politécnico de Bragança (IPB) for creating such an important exchange opportunity. 


\section{Abstract}

The transport sector plays a fundamental role in the European economy. Efficient transport services and infrastructure are fundamental for making the most of the region's economic strengths. Unfortunately, the European Union transport sector still remains heavily dependent on oil resources and, therefore, it is responsible for a large part of the air pollution. The emissions from the sector have reduced in the last decade, but not enough to limit its impact on the environment and climate. Reducing its pressure on the environment is critical to achieve long-term sustainability. The European Union has been promoting diverse initiatives towards sustainable transport development and environment protection by setting targets for changes in the sector as the ones proposed in 2011 White Paper on transport. Under this context, this study aims at evaluating the environmental performance of the transport sector in 28 European Union countries, from 2015 to 2018, towards the policy agenda established in the strategic documents. The assessment of the transport environmental performance was made through the aggregation of seven sub-indicators into a composite indicator using a Data Envelopment Analysis approach. Two models were first used to determine the weights to aggregate the subindicators: the conventional Benefit of the Doubt model and a variant of the model, both with virtual proportional weights restrictions. The results indicate that the European Union countries have been improving their transport environmental performance in the last two years analysed, 2017 and 2018. The inefficient countries should improve the transport sustainability mainly by drastically reducing the greenhouse gas emissions from fossil fuel, increasing the share of freight transport that uses rail and inland waterways and also the share of transport energy from renewable sources.

Keywords: composite indicator, sustainable development, Data Envelopment Analysis, Benefit of the Doubt. 


\section{Resumo}

O sector dos transportes desempenha um papel fundamental na economia europeia. Serviços e infraestruturas de transporte eficientes são fundamentais para tirar o máximo proveito do potencial económico da região. Infelizmente, o setor de transportes da União Europeia ainda permanece fortemente dependente de recursos petrolíferos e, portanto, é responsável por grande parte da poluição do ar. As emissões do setor foram reduzidas na última década, mas não o suficiente para limitar seu impacto no meio ambiente e no clima. Reduzir sua pressão sobre o meio ambiente é fundamental para alcançar a sustentabilidade de longo prazo. A União Europeia tem vindo a promover diversas iniciativas para o desenvolvimento sustentável dos transportes e a proteção do ambiente, estabelecendo metas para as mudanças no setor, como as propostas no White Paper dos transportes de 2011. Neste contexto, o presente estudo tem como objetivo avaliar o desempenho ambiental do setor dos transportes em 28 países da União Europeia, de 2015 a 2018, em relação a agenda política estabelecida nos documentos estratégicos. A avaliação do desempenho ambiental do transporte foi feita através da agregação de sete sub-indicadores em um índice compósito usando uma abordagem de Data Envelopment Analysis. Dois modelos foram usados para determinar os pesos para agregar os sub-indicadores: o modelo convencional do Benefit of the Doubt e uma variante desse modelo, ambos com restrições de pesos. Os resultados indicam que os países da União Europeia têm melhorado o seu desempenho ambiental no sector de transportes nos últimos dois anos analisados, 2017 e 2018. Os países ineficientes devem melhorar a sustentabilidade do transporte principalmente reduzindo drasticamente as emissões de gases de efeito estufa provenientes da queima combustíveis fósseis, aumentando a parcela do transporte de carga que utiliza ferrovias e hidrovias e também a parcela da energia do transporte de fontes renováveis.

Palavras-chave: índice compósito, desenvolvimento sustentável, Data Envelopment Analysis, Benefit of the Doubt. 



\section{Contents}

List of Tables $\quad$ xi

List of Figures $\quad$ xii

Acronyms

List of Symbols $\quad$ xiv

1 Introduction $\quad 1$

1.1 European transport sector . . . . . . . . . . . . . . . 1

1.2 European strategies for the transport sector . . . . . . . . . . . 2

1.3 Problem formulation $\ldots \ldots \ldots \ldots \ldots$

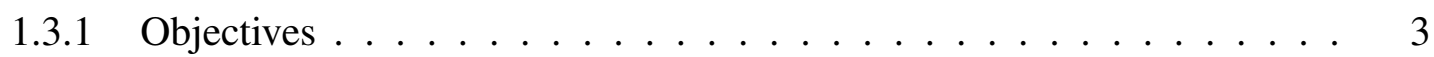

1.4 Structure of the thesis . . . . . . . . . . . . . . 4

$\begin{array}{lll}2 & \text { State of the art on composite indicators } & 7\end{array}$

2.1 Composite indicators . . . . . . . . . . . . . . 7

2.2 Data Envelopment Analysis (DEA) . . . . . . . . . . . . . . . . 10

2.3 Benefit of the Doubt $(\mathrm{BoD})$ model $\ldots \ldots \ldots \ldots$

2.4 BoD model with additional restrictions . . . . . . . . . . . . . . . . 15

2.5 Transformation of anti-isotonic sub-indicators . . . . . . . . . . 16

2.5.1 FKHM model . . . . . . . . . . . . . . . 18

3 Application and analysis of the BoD model 21

3.1 Application of the BoD . . . . . . . . . . . . . . 21 
3.2 Analysis of the transformation techniques for anti-isotonic sub-indicators $\ldots .24$

4 Indicators to assess transport environmental performance 29

4.1 Transport sustainable development . . . . . . . . . . . . . . . 29

4.2 Data and variables . . . . . . . . . . . . . . . . 33

4.2 .1 Correlation analysis . . . . . . . . . . . . 38

5 Results and discussions $\quad 43$

5.1 Descriptive analysis of the variables . . . . . . . . . . . . . 43

5.2 Performance assessment of the EU countries . . . . . . . . . . . . . . 46

5.2 .1 Benchmark analysis ........................ 51

5.2 .2 Radar analysis . . . . . . . . . . . . . . . 53

5.3 CI results versus environmental taxes revenues . . . . . . . . . . . 55

6 Conclusions $\quad 59$

$\begin{array}{lll}\text { References } & 61\end{array}$

$\begin{array}{lll}\text { A Additional tables } & 65\end{array}$

$\begin{array}{llr}\text { B BoD reverse indicators code } & 68\end{array}$ 


\section{List of Tables}

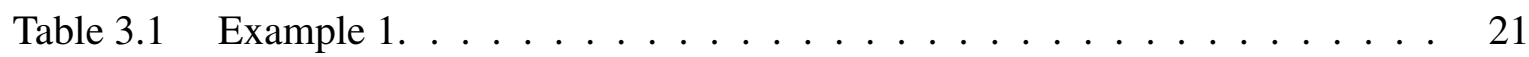

Table 3.2 Weights and CI's results. . . . . . . . . . . . . 22

Table 3.3 Weights and CI's results using model 2.4 with additional sub-indicator share restriction $(2.6) . \ldots \ldots . \ldots \ldots 23$

Table 3.4 Example 2. . . . . . . . . . . . . . . . . . . . 24

Table 3.5 CI's results with different transformation techniques for the anti-isotonic sub-indicator. . . . . . . . . . . . . . . . 27

Table 4.1 Sustainability goals - triple bottom line. Source: Adapted from [30]. . . . 30

Table 4.2 Sustainability sub-indicators found in literature. . . . . . . . . . . . 32

Table 4.3 Sub-indicators correlation matrix and p-values. . . . . . . . . . . . . 40

Table 4.4 Sub-indicators selected. . . . . . . . . . . . . . . . . . 41

Table 5.1 Mean and DC of the indicators data used in the construction of the CI. . 44

Table 5.2 CI results using the FKHM model with countries ranked by their average CI results . . . . . . . . . . . . . . . . . . 50

Table 5.3 Comparison between the sub-indicator values from Portugal and the its target benchmark values. . . . . . . . . . . . . . . 53

Table 5.42018 CI results and transport environmental taxes. . . . . . . . . . . 56

Table A.1 Transport environmental performance results. . . . . . . . . . . . . . 65

Table A.2 Benchmarks used by each country. . . . . . . . . . . . . . 66

Table A.3 CI results and transport environmental taxes. . . . . . . . . . . . 67 


\section{List of Figures}

Figure 3.1 Efficiency Frontier. . . . . . . . . . . . . . . . . . . . . 22

Figure 3.2 Results from the different transformation techniques for the anti-isotonic sub-indicators. . . . . . . . . . . . . . . . . 26

Figure 5.1 Boxplot of the forward sub-indicators data. . . . . . . . . . . . . 46

Figure 5.2 Boxplot of the reverse sub-indicators data. . . . . . . . . . . . . . 47

Figure 5.3 Evolution of the average of the EU countries' CI score from 2015 to 2018. 49

Figure 5.4 Map of the countries CI results from 2018 . . . . . . . . . . . . . . 51

Figure 5.5 Frequency of use of the benchmarks. . . . . . . . . . . . . . 52

Figure 5.6 Comparison between benchmarks and inefficient countries. . . . . . . . 54

Figure 5.7 Variation of the $\mathrm{CI}$ average and the transport environmental taxes average. 55

Figure 5.8 Comparison between the CI results and the 2018 transport environmental

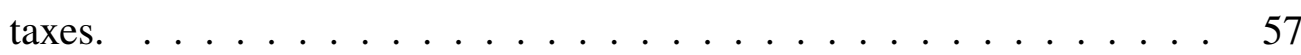




\title{
Acronyms
}

\author{
AHP Analytic Hierarchy Process \\ BoD Benefit of the Doubt \\ $\operatorname{BoD}(\mathbf{K})$ Conventional BoD model, using the Constant linear transformation \\ technique to transform the data of the anti-isotonic sub-indicators \\ CI Composite Indicator \\ DC Dispersion Coefficient \\ DEA Data Envelopment Analysis \\ DMU Decision Making Unit \\ EPI Environmental Performance Index \\ EU European Union \\ FA Factor Analysis \\ FKHM Variant of the BoD model proposed by R. Färe, G. Karagiannis, \\ M. Hasannasab and D. Margaristis (2019) \\ GDP Gross Domestic Product \\ GHG Greenhouse gas \\ HDI Human Development Index \\ PCA Principal Component Analysis \\ pkm passenger-kilometer \\ tkm tonne-kilometer
}




\section{List of Symbols}

\begin{tabular}{ll}
\hline \hline Symbol & Description \\
\hline \hline$w_{i}$ & Weight for sub-indicator/output $i$ \\
$y_{i j}$ & Sub-indicator/output $i$ for unit $j$ \\
$e_{j_{0}}$ & Efficiency ratio \\
$v_{k}$ & Weight for input $k$ \\
$x_{k j}$ & Input $k$ for unit $j$ \\
$\alpha$ & Minimum percentage required for the sub-indicator share \\
$\beta$ & Maximum percentage required for the sub-indicator share \\
$\mathrm{K}$ & Positive constant \\
$Y_{\text {min }}$ & Sample minimum value \\
$Y_{\text {max }}$ & Sample maximum value \\
$\lambda_{j}$ & Degree of intensity of each benchmark $j$ in each country's evaluation \\
$r$ & Correlation coefficient \\
$s_{X Y}$ & Covariance of $X$ and $Y$ datasets \\
$s_{X}$ & Standard deviation of sub-indicator X \\
$s_{Y}$ & Standard deviation of sub-indicator Y \\
$n$ & Number of observations \\
$d f$ & Degrees of freedom \\
\hline \hline
\end{tabular}




\section{Chapter 1}

\section{Introduction}

\subsection{European transport sector}

The transport sector plays a fundamental role in the European economy by providing services to citizens and businesses and its demand is closely linked to economic growth [1]. By 2017, the transport sector employed directly more than 11 million people, around $5 \%$ of the total workforce, and its activities accounted for about 5\% of Europe's Gross Domestic Product (GDP) [2]. In 2017, the European Union (EU) total passenger transport by motorized means, including land, sea and air transport, was estimated at around 6913,3 billion passenger-kilometre or 13.505 kilometres per person [3].

Efficient transport services and infrastructure are fundamental for making the most of the economic strengths of all EU regions and supporting the internal market and its growth [2]. Between 2010 and 2050, passenger transport activity is expected to grow by $42 \%$ and freight transport activity by $60 \%$ [4]. Unfortunately, the EU transport sector still remains heavily dependant on oil resources and, therefore, it is responsible for a large part of the air pollution. In 2015, greenhouse gas (GHG) emissions from the transport sector reached $22 \%$ of the total European GHG emissions [5]. According to the Transport and Environment Reporting Mechanism [6], the emissions from the sector have reduced in the last decade, but not enough to limit their impact on the environment and climate.

Since the transport sector is a key factor in the European economy, reducing its pressure on the environment is critical to achieve long-term sustainability [6]. An effective and sustainable transportation system should contribute positively to the economic growth, to social development through the fair use of the natural resources allied to environmental protection [1]. 


\subsection{European strategies for the transport sector}

Under the scenario previously introduced, the European Commission's White Paper on transport - Roadmap to a Single European Transport Area - Towards a competitive and resource efficient transport system, from 2011 [7], identified the main challenges in the EU transport sector and proposed strategies for deep changes in the European transport sector aiming at a more sustainable and efficient system.

Some of the targets addressed in the Roadmap include: achieving a $60 \%$ reduction in GHG emissions by 2050 with respect to 1990 , phasing out conventionally fuelled cars from cities by the same year and improving the road safety. The paper also highlights the development of a Single European Transport Area, with the objective of connecting Europe with a efficient, modern, safe and multi-modal transport network allowing the exploitation of the economic strength of all European regions and enabling more economic and social cohesion.

The prospect of a more efficient transport service can affect citizens and businesses tangibly, as transport and logistics amount to a sizeable share of companies and households costs. On average, a household spends $13 \%$ of it's budget on transport. For business that deal with high value products or services, the cost of transport may not be so significant. However, a reliable transport system is fundamental to ensure the functioning of increasingly complex value chains [2].

Another initiative is the United Nations' Sustainable Development Goals that aims to achieve a more sustainable future for everyone. These goals address global challenges in several areas such as poverty, inequality and climate change, in a total of 17 goals [8]. Improvements in the transport sector are very important for achieving many of these goals as several of them are related to transport sustainability. These targets were highlighted in [9]. Some are directly related to the transport sector while others are related to areas where transport has an important impact, such as energy consumption and emissions. The United Nations also emphasizes the interconnection of all goals and the importance of achieving them by 2030 [8]. 


\subsection{Problem formulation}

The sustainable development of the transport sector has been put on the agenda, making clear the necessity to measure and assess the current transport environmental performance concerning the EU countries in the direction of these targets. It also highlights the importance of analysing sustainable transport planning, as transport policy and planning decisions can have diverse and long-term impacts on sustainable development. A critical component of sustainable transport planning is the development of a comprehensive evaluation program that assesses the transport performance based on an appropriate set of sub-indicators [10].

Sub-indicators are increasingly being used to measure and assess the sustainability of transport. Their use is fundamental to make these targets operational, and define the actions needed to achieve them. Even though sub-indicators are useful tools, they also have their limitations, for instance, a single sub-indicator cannot provide a complete description of a multi-faceted phenomenon [11]. Sustainability of the transport sector is a multi-faceted subject and assessing it requires the use of many sub-indicators. However, the analysis of several sub-indicators is complex for decision making, as a joint interpretation is difficult. The best approach is to aggregate the individual sub-indicators for each country into a single index, the composite indicator (CI). The CI is a practical approach that allows to summarize, compare and track the performance of the countries. It allows the measurement of complex and multi-faceted issues that cannot be captured completely by individual sub-indicators [12].

Developing a CI to assess sustainability is a complex theoretical and methodological task, since there is still no general agreement on the concept of sustainable transport and on how and what sub-indicators should be used to measure it appropriately [13]. The construction of the CI also involves choices among different normalization, weighting, and aggregation techniques and these choices can significantly impact the results.

\subsubsection{Objectives}

The objective of this study is to measure and evaluate the environmental performance of the transport sector in the EU-28 countries, from 2015 until 2018, towards a more sustainable 
mobility by using composite indicators. It aims at showing the usefulness of a DEA-based model, the Benefit of the Doubt $(\mathrm{BoD})$ model, in assessing the relative environmental performance of the EU countries by aggregating data from a set of sub-indicators into a single composite indicator.

To achieve this objective the following tasks were set:

- identify and select relevant transport sub-indicators;

- process and analyse the sub-indicators' data;

- research and apply different transformation techniques for negative or anti-isotonic subindicators;

- improve the algorithm for the BoD model in order to aggregate the reverse sub-indicators using the Färe et al. [14] model;

- calculate the environmental performance of the EU-28 countries using the conventional BoD model and a variant of the model and compare the results of both methods;

- rank and assess the countries performance using the $\mathrm{CI}$ results.

\subsection{Structure of the thesis}

Besides the first chapter, presenting the motivation and the objectives of the work, this dissertation is organized into five more chapters as follows.

- Chapter 2: Literature review on composite indicator, its usefulness and construction characteristics. It also addresses the different weighting methods used in CI construction, focused on the BoD method.

- Chapter 3: Application of the BoD model in a simplified problem to address the outcomes interpretation. Additionally the transformation techniques for the anti-isotonic sub-indicators is analysed and the BoD model, proposed by Färe et al. [14], is also presented. 
- Chapter 4: Literature review on transport sustainability, the application of transport subindicators and the selection of the sub-indicators to compute the CI.

- Chapter 5: Descriptive analysis of the sub-indicators data. Development of the CI using two BoD models, analysis of the results and of the areas that need improvement. Comparison between the CI result and the transport environmental taxes.

- Chapter 6: Presentation of the conclusions from this work and suggestions for future work. 



\section{Chapter 2}

\section{State of the art on composite indicators}

This chapter presents a literature review on composite indicator and the methodology behind its construction. Techniques for dealing with zero weights and anti-isotonic sub-indicators are also presented, along with the BoD model proposed by Färe et al. [14].

\subsection{Composite indicators}

The composite indicator has been proven to be a useful tool to synthesize masses of data, benchmark countries performance in relation to desirable states, demonstrate progress towards goals and to communicate current status to stakeholders leading to effective management decisions towards the established targets [15]. It is also a recognized tool for public communication, since they provide a big picture of a subject and often make it easier for the general public to interpret its results rather than having to identify common trends across many sub-indicators [16]. Therefore, CI usually shows up on media headlines and press releases of well-respected international organizations. Some really well-known composite indicators are the Human Development Index (HDI), that rank countries based on life expectancy, education and per capita income sub-indicators; and the Environmental Performance Index (EPI), which uses 32 sub-indicators to evaluate the state of sustainability of the countries [17].

The essential purposes of the composite indicator are to summarize a complex, multifaceted phenomena in wide-ranging fields, e.g. environment, economy, society or technological development, and compare the performance of several units or the evolution of a unit over time [18]. The CI comprises several individual sub-indicators that measure different aspects, usually with no unit of measurement in common. The sub-indicators are compiled into a single index on the premise of an underlying model much like mathematical and computational models. And 
just like a mathematical or computational model, CI construction depends primarily on the craftsmanship of the modeller than universally accepted rules [16].

However, CI results can easily give rise to misuse and misinterpretation and users can be lead to draw simplistic analytical or policy conclusions. Given that summarizing reduces the available information, it can often obscure essential parts of this data. Also, the lack of a standard construction methodology and the subjectivity involved in this process make Composite Indicators a subject of controversy [18]. Thus, the underlying model and construction process should be very transparent and comprehensive and the CI must be considered more as a mean to stimulate discussion and public interest, and not so much as the only pillar of information and decision making [16].

The Handbook of Constructing Composite Indicators [16] divides the development of the $\mathrm{CI}$ in ten steps helping the builder to make the appropriate choices during the process. Some of those steps are the development of the theoretical framework, the selection of the data and the use of weighting and aggregation methods. Noticeably, the practicality and robustness of a CI depends heavily on the underlying weighting and aggregation methods [17].

When aggregating the sub-indicators in a composite indicator, it is necessary to assign weights to each of them according to the underlying theoretical framework. There is a wide range of weighting approaches that can be used to derive the weights for each sub-indicators [16]. Considering $m$ sub-indicators, for each country $j, y_{i j}(i=1, \ldots, m)$ the formulation presented in (2.1) shows the $\mathrm{CI}$ formulation in a general level. Thus, the sub-indicators are aggregated into $\mathrm{CI}_{j}$ that can be used to evaluate the performance of country $j$ with respect to all $m$ sub-indicators.

$$
\mathrm{CI}_{j}=\sum_{i=1}^{m} w_{i} y_{i j}
$$

The subjective judgment about the relative worth of each sub-indicator enters through the weights assigned to them [18]. The weights reflect the significance of the sub-indicator and attributes value to it in regards to the others. They usually have a great impact on the aggregation results. Therefore, the weighting method needs to be made explicit and transparent. Besides, no matter the methodology employed, the subjective component of the weights is basically value 
judgments and should make the objectives underlying the aggregation clear [11].

The weights attributed to the sub-indicators can be derived through different methods. The easiest and most common approach is to use equal weights. However, as it will be further discussed, not all units agree to be evaluated with equal weights, since each of them has different characteristics and preferences. The weights can also be based on opinions, such as expert judgment or public opinion poll results. Finally, the third method, to avoid the subjectivity in the determination of the sub-indicators' weights, the preferred tools are those statistical methods that derive them endogenously, such as the Principal Component Analysis/Factor Analysis and deterministic method such as the the Data Envelopment Analysis [17].

The equal weights aggregation method is applied to numerous indexes, such as the Human Development Index and the Environmental Sustainability Index [1]. In this method all the sub-indicators are assumed to have the same impact on the composite indicator value [12]. The equal weights method is regularly used as the standard because of its simplicity, however this is often misleading. Since the aggregation using equal weights is not a unit invariant method, the data for each sub-indicator needs to be normalized in order to be aggregated. However, different normalization methods can lead to different CI and ranking results and, therefore, the countries ranking would depend on the normalization option taken [18]. Also, the implicit assumption that each sub-indicator has the same importance might not be true, and there is a risk that certain aspects are double-counted since this method cannot correct overlaps if two or more indicators are correlated [13].

Besides, it is unnecessary restrictive to assume there is an equality across nations in different objectives. The equal weights assumption ends up penalizing countries for a successful pursuit of some objectives, at the expense of not succeeding in another conflicting objective [18]. Specially in the European context, a flexible weighting system is necessary as the choice of the weights can lead to tensions and the precise way by which the countries policies are evaluated can be questioned [18].

There are many methods to summarize expert or public judgment, when the weights are derived from experts' or the public's opinion. It has been very popular to use multi-criteria methods such as the widely used Analytic Hierarchy Process (AHP). This approach uses pairwise 
comparisons between the sub-indicators to evaluate qualitative and quantitative aspects of a problem. Experts have sub-indicators presented in pairs in order to indicate which of the two sub-indicators is more important in their opinion and how much more important. The weights in this method represent a trade-off between the sub-indicators and cannot be interpreted as importance coefficient [12]. The AHP method, therefore, depends on the consistency of people's or experts' opinions in the comparison matrix. Besides, weights coming from stakeholders can often be characterized by strong individual disagreements [18]. Reisi et al. [12] argue that this method should only be used when less than 10 sub-indicators are being compared.

The methods that derive the weights of the sub-indicators from the data itself presented in this work are the statistical one, the Principal Component Analysis/Factor Analysis and the deterministic one, the Data Envelopment Analysis.

The Principal Component Analysis/Factor Analysis (PCA/FA) is a popular approach to derive the weights for the sub-indicators. The method basically relies on the variation and covariation of the data to attribute the weights and construct the indexes [12]. PCA groups together the collinear sub-indicators into a new uncorrelated variable named principal component. Each principal component is a composite index of the original sub-indicators. It captures as much information of individual sub-indicators as possible, to represent the overall data while affording data reduction with minimum loss of the original information. FA follows PCA to reduce the contribution of less significant sub-indicators and simplify even more the data structure. The correlations between sub-indicators are very important, as the weights cannot be estimated when there are no correlated sub-indicators. However, the correlation should not be due to the redundancy of the information. The PCA/FA is sensitive to data modification, the presence of outliers and small samples of units [12].

\subsection{Data Envelopment Analysis (DEA)}

The DEA is a deterministic method, proposed by Charnes et al. [19], that evaluates the relative efficiency of several decision making units (DMU) based on linear programming. The DMU is the entity under assessment that uses multiple inputs to produce multiple outputs. The flexibility 
in the definition of the DMU allows it to be used on a wide range of applications [20]. Therefore, DEA measures the efficiency of each DMU, given observations on input and output values in a set of similar entities, without knowledge of the production or cost function [18]. By comparison with the best practices frontier, the DEA model enables the selection of weights that are the most advantageous for the DMU under assessment [12]. This means that the weights are derived from the data itself, avoiding a priori assumptions and computations involved in the fixed weight choices [20].

As by-product of DEA, each DMU is classified as efficient or inefficient. The linear combination of the efficient DMUs creates the efficiency frontier of best practices used as reference to calculate the efficiency of each DMU. The efficient DMUs on the frontier have a efficiency score equal to 1 (or 100\%). While the DMUs outside the frontier, the inefficient ones, have an efficiency score less than 1. The envelopment part of the DEA comes from this property, since the frontier is said to "envelop" the observed DMUs. The efficiency frontier is the basis to measure the relative efficiency of the observed DMU by using its distance to the frontier. DEA also can be used to rank the DMU based on their performance for a given mix of inputs and outputs [20].

The DEA enables to measures the DMUs efficiency in terms of Pareto-Koopmans concept which is obtained when an increase in any output requires a decrease in at least another output or an increase in at least another input, or when a decrease in any input requires the increase of at least another input or the decrease in at least another output [21].

In the simple case of a single input and output, the efficiency score is calculated through the ratio between a single output and a single input. The basic DEA model uses the same idea, but uses the ratio between the weighted sum of multiple outputs by the weighted sum of multiple inputs. The efficiency of DMU is defined as the maximum ratio that it transforms inputs into outputs. Mathematically, the DEA obtains the efficiency $e_{j_{0}}$ of each assessed $\mathrm{DMU}_{j_{0}}$ by maximizing the ratio of the weighted outputs over the weighted inputs by comparison with the levels of inputs and outputs in all observed DMU [22]. This fractional formulation is presented in (2.2), in which it is assumed that a set of $j=1, \ldots, s$ DMUs uses $x_{k}(k=1, \ldots, n)$ inputs to produce $y_{i}(i=1, \ldots, m)$ outputs. Denote $w_{i}$ as the output weights and $v_{k}$ as the input weights. The $\mathrm{DMU}_{j_{0}}$ 
total virtual output is defined by $\sum_{i=1}^{m} w_{i} y_{i j_{0}}$ and its total virtual input by $\sum_{k=1}^{n} v_{i} y_{k j_{0}}$. The objective of the model is to obtain the weights $w_{i}$ and $v_{k}$ that maximize the ratio of the total output by the total input of the DMU being assessed, $\mathrm{e}_{j_{0}}$.

$$
\begin{array}{ll}
\max & \mathrm{e}_{j_{0}}=\frac{\sum_{i=1}^{m} w_{i} y_{i j_{0}}}{\sum_{k=1}^{n} v_{k} x_{k j_{0}}} \\
\text { s.t. } & \frac{\sum_{i=1}^{m} w_{i} y_{i j}}{\sum_{k=1}^{n} v_{i} x_{k j}} \leq 1 \quad \forall j=1, \ldots, s \\
& w_{i}, v_{k} \geq 0 \quad \forall i=1, \ldots, m ; \quad k=1, \ldots, n
\end{array}
$$

Therefore, the weights set are peculiar for each unit and are selected according to the convenience of the DMU under evaluation, $\mathrm{DMU}_{j_{o}}$ in this case. The objective function is subject to the constraints that the efficiency ratios of all DMUs in the sample computed with those weights have an upper bound of one and all the weights are non-negative.

The weights are determined in a way to show each of DMU in the best way possible, i.e., maximizing the resulting output-input ratio for each unit relative to all others, when the same weights are assigned to the inputs and outputs of all DMUs. This best result is general and the DMU being evaluated cannot choose a better set of weights, as long as these three conditions are guaranteed: all data and all weights are non-negative, the resulting ratio must lie between zero and one and these same weights for the target entity are applied to all entities [20].

Since the weights are obtained endogenously, this implies they are flexible to adapt to the input and output units of measurement. This leads to another well-known property of the original DEA model: its unit invariance. This means that the efficiency score is unaffected by the different units used, but the weights are not, since they do depend on the units of measurement [18].

Formulation (2.2) is a case of fractional programming. To deal with it Charnes et al. [19] proposed to norm the total virtual input, so that $\sum_{k=1}^{n} v_{k} x_{k j_{0}}=1$, achieving the DEA model presented in (2.3). This model is input oriented as it maximises the total virtual output of the DMU by setting the total virtual input to one [23]. 


$$
\begin{array}{ll}
\max & \mathrm{e}_{j_{0}}=\sum_{i=1}^{m} w_{i} y_{i j_{0}} \\
\text { s.t. } & \sum_{i=1}^{m} w_{i} y_{i j}-\sum_{k=1}^{n} v_{k} x_{k j} \leq 0 \quad \forall j=1, \ldots, s \\
& \sum_{k=1}^{n} v_{k} x_{k j_{0}}=1 \\
& w_{i}, v_{k} \geq 0 \quad \forall i=1, \ldots, m ; \quad k=1, \ldots, n
\end{array}
$$

The input oriented and the output oriented models are used to identify which input and output values can be improved to make the unit more efficient [21]. In the input oriented analysis the outputs are kept fixed. This way, the model shows how much the inputs can be reduced without affecting the outputs. On the other hand, the output oriented analysis keeps the inputs fixed to show by how much the outputs can be increased without affecting the inputs.

\subsection{Benefit of the Doubt (BoD) model}

The application of DEA to the construction of composite indicators, referred to as the Benefit of the Doubt model (BoD), was originally proposed by Melyn and Moesen in 1991 [24]. The BoD model is equivalent to the original DEA input oriented model (2.3), with all sub-indicators considered as outputs and a single dummy input equal to one for all DMU. The dummy input can be understood intuitively by regarding the model as a tool for aggregating several sub-indicators of performance, without referencing the inputs that are used to obtain this performance [25]. Since the BoD model only includes outputs it measures the DMU's performance rather than its efficiency.

As stated before, the objective is to aggregate the individuals sub-indicators (the outputs) for each country into a single composite indicator defined as the weighted average of $m$ subindicators. Given a cross-section of $m$ sub-indicators and $s$ countries, with $y_{i j}$ being the value of sub-indicator (or output) $i$ for the country $j$, and $w_{i}$ the weight attributed to the $i$-th sub-indicator. These weights are endogenously calculated using the DEA model (2.4) for each country under evaluation $j_{0}$. The $\mathrm{CI}$ is computed for each country $j_{0}$, through the BoD model presented in 
(2.4).

$$
\begin{array}{ll}
\mathrm{CI}_{j_{0}}= & \max \sum_{i=1}^{m} w_{i} y_{i j_{0}} \\
\text { s.t. } & \sum_{i=1}^{m} w_{i} y_{i j} \leq 1 \quad \forall j=1, \ldots, s \\
& w_{i} \geq 0 \quad \forall i=1, \ldots, m
\end{array}
$$

For each DMU under evaluation, the model chooses the $w_{i}$ for each sub-indicator $y_{i}$ that maximizes its $\mathrm{CI}_{j_{0}}$ score. This implies that the highest relative weights are assigned to those dimensions in which the country has the best relative performance when compared to the other countries [26]. The benefit of the doubt idea is related to DEA deriving the weights and the countries benchmarks from the data itself. The core idea is as follows: if a sub-indicator has a good relative performance it suggests that this country views this policy dimension as relatively important, so it deserves a higher weight. The opposite is also valid, i.e., a sub-indicator with a low relative performance indicates a lower importance attached by the country in that context, therefore it receives a lower weight. Therefore, countries cannot claim that a poor relative performance is due to a harmful or unfair weighting scheme, as the model perspective chooses specific weights that make the CI as high as possible [18].

The formulation 2.4 has two kinds of restrictions. The first restriction imposes that no country can have a CI value greater than one, to ensure an intuitive interpretation of the indicator. The second restriction imposes that each weight attributed to the sub-indicators should be non-negative, which implies that the $\mathrm{CI}$ is a non-decreasing function of the sub-indicators. Consequently, the CI value obtained varies between zero and one for each assessed country $j_{0}$, where higher values indicate a better relative performance [26].

The benchmarks are the countries that, employing the same weights in a given set of subindicators, obtained the maximal weighted sum of them, that is, a CI equal to one. Therefore, each inefficient country can be compared with a different set of benchmarks, using specific set of weights [18]. This means that there is at least one other country which, using the same weighting scheme for the same set of sub-indicators as the country assessed, does even better and achieve a 
CI score of one [18].

As the BoD formulation (2.4) is a DEA model, it also preserves the useful properties of that model, such as the endogenous estimation of weights and the units invariance. This is very interesting for the construction of $\mathrm{CI}$ as the DEA solves the problem of subjectivity in the weighting procedure and its final CI scores are independent of the measurement units of the sub-indicators. This fact makes the normalization stage redundant, eliminating the results dependency on the normalization method used [26].

\subsection{BoD model with additional restrictions}

Apart from the required non-negativity of the weights, the BoD model presented in (2.4) allows the weights to be freely estimated in order to maximize the relative performance of the country under evaluation. However, there are also disadvantages to this full flexibility. In some situations, a country may obtain a higher relative performance by assigning zero weights to some subindicators that have worse scores. This means that the sub-indicator associated with the zero weight has no influence in the global performance and the CI scores may end up being based in a small subset of all the sub-indicators. This situation should be avoided, since the sub-indicators are usually carefully selected and, therefore, they are all deemed important in computing the CI [23].

To prevent sub-indicators from being over or under emphasized, the model can incorporate additional restrictions for the sub-indicator weights. The weight restrictions can be absolute weight bounds, weight ratio bounds, or restrictions to the sub-indicators share [23]. The subindicator $i$ share is given by $\frac{w_{i} y_{i j_{0}}}{\sum_{i=1}^{m} w_{i} y_{i j_{0}}}$ and measures how much dimension $i$ contributes to the overall composite score of country $j_{0}$ [18]. Since measurement units cancel out, each subindicator share is completely independent of measurement units facilitating their interpretation. By adding the sub-indicator share restriction, as proposed by [27] and shown in (2.5), each sub-indicator share is required to have a minimum percentage $\alpha$ and a maximum percentage $\beta$ of contribution in the assessed CI. 


$$
\alpha \leq \frac{w_{i} y_{i j_{0}}}{\sum_{i=1}^{m} w_{i} y_{i j_{0}}} \leq \beta \quad \forall i=1, \ldots, m
$$

The weight restriction is a great tool to make the model more discriminating in performance assessment. However, it is a value judgement, as it is decided by the modeller that the situation is better represented if such limits are imposed [18]. By setting bounds on a sub-indicator share it implicitly affects the values that the remaining shares can take. Also, binding constraints imply that a country would have done better if these bounds had been relaxed, and therefore, the option to use these restrictions need to be meaningful and justified [23]. The unfortunate result of over restricting the sub-indicator shares is that it may be no feasible solution to the programming problem [18].

The approach on weight restriction used in this work was the same used by Färe et al. [14]. As the interest is to prevent the model to assign zero weights to the sub-indicators, a lower bound to the sub-indicator share is defined while keeping the upper bound free, as presented in (2.6).

$$
\frac{w_{i} y_{i j_{0}}}{\sum_{i=1}^{m} w_{i} y_{i j_{0}}} \geq \alpha \quad \forall i=1, \ldots, m
$$

\subsection{Transformation of anti-isotonic sub-indicators}

The conventional $\mathrm{BoD}$ model derives the composite indicator by aggregating forward subindicators, which capture the positive aspect of a performance, where their increasing values are desirable. Frequently, however, the performance assessment has to manipulate anti-isotonic sub-indicators, which capture the negative aspect of a performance, where their increasing values are not desirable. There are many sub-indicators that fall in this category, for example, emission of a pollutant, traffic accidents, crime rate, etc [14].

Possible approaches to deal with these anti-isotonic sub-indicators are the use of data transformation techniques. The values of these sub-indicators are transformed to allow them to be incorporated in the conventional BoD model and treated as the forward sub-indicators [14]. One of the most common data transformation technique is the inversion of the value 
of the undesirable sub-indicator [28]. The subtraction of the sub-indicator from a sufficiently large constant and the rescaling normalization using the maximum-minimum method are also approaches that can be found in the literature. Some of these techniques are presented and compared in [23] and [29].

In the data transformation method referred as the Inversion method, that consists of transforming the undesirable output by inverting its values as in $f_{i j}(Y)=1 / y_{i j}$, where $Y$ is the matrix of undesirable sub-indicators. However, this method destroys the ratio or interval scale of the data [23].

Another way of treating these undesirable sub-indicators is through the Constant method. This method consists of subtracting these sub-indicator values from a sufficiently large positive constant $\mathrm{K}$, using the transformation $f_{i j}(Y)=\mathrm{K}-y_{i j}$. However, this technique is sensitive to the choice of the constant $\mathrm{K}$, as a large value can dominate the data and change the efficiency frontier. A smaller value $K$ is, therefore, more adequate as it reduces the effect of the translation on the results [23].

A third method is the Maximum-Minimum (MM) method. In this the undesirable subindicators are normalized through their division by the difference between its sample maximum $\left(Y_{\max }\right)$ and minimum $\left(Y_{\min }\right)$. This normalization is commonly used on forward sub-indicators and is given by $f_{i j}(Y)=\left(y_{i j}-Y_{\min }\right) /\left(Y_{\max }-Y_{\min }\right)$. However, as previously stated, when using a DEA model the normalization step is redundant and not necessary. Although, a variation of this normalization, as employed in [22], is interesting for undesirable sub-indicators as it can be used to transform their values into forward values. In this case, the normalization is given by $f_{i j}(Y)=\left(Y_{\max }-Y_{i j}\right) /\left(Y_{\max }-Y_{\min }\right)$. The normalized sub-indicators values vary in a dimensionless range of zero to one, in which zero is the worst result and one is the best. However, restrictions have been added to prevent the sub-indicator shares to be zero and zero-valued sub-indicator is not desirable. Therefore the maximum and minimum observations for each sub-indicator were replaced by constants with values close to the original, and so the rescaling is still proportional but the extreme values are avoided.

Even though these transformation are simple, they can be problematic. Since the BoD model is derived from an input-oriented DEA model with constant returns to scale and it is not 
translation invariant for the output values [14]. This means that, the use of translated or rescaled data will affect the CI results and, consequently, the ranking of the DMU.

\subsubsection{FKHM model}

R. Färe, G. Karagiannis, M. Hasannasab and D. Margaristis [14] proposed a new BoD model, which directly incorporates the anti-isotonic sub-indicators without using any transformation. In this work the model is referred to by the authors initials as FKHM model. The FKHM model treats the anti-isotonic sub-indicators as reverse rather than as undesirable. This means that the model assumes that the reverse sub-indicators values can decrease or increase independently from the values of forward sub-indicators.

Given a cross-section of $M$ sub-indicators and $s$ countries, $y_{i j}$ is the value of sub-indicator $i$ for the country $j$, and $w_{i}$ is the weight attributed to the $i$-th sub-indicator. The formulation for the FKHM model is presented in Eq.(2.7), where $y_{i j}(j=1, \ldots, m)$ are the forward sub-indicators (i.e., capturing positive aspect) and $y_{i j}(j=m+1, \ldots, M)$ are the reverse sub-indicators (i.e., capturing negative aspect).

$$
\begin{array}{cl}
\mathrm{CI}_{j_{0}}= & \max \sum_{i=1}^{m} w_{i} y_{i j_{0}}-\sum_{i=m+1}^{M} w_{i} y_{i j_{0}} \\
\text { s.t. } & \sum_{i=1}^{m} w_{i} y_{i j}-\sum_{i=m+1}^{M} w_{i} y_{i j} \leq 1 \quad \forall j=1, \ldots, s \\
& w_{i} \geq 0 \quad \forall i=1, \ldots, M
\end{array}
$$

The dual formulation of (2.7) is given by (2.8).

$$
\begin{array}{ll}
\min & \sum_{j=1}^{s} \lambda_{j} \\
\text { s.t. } & \sum_{j=1} \lambda_{j} y_{i j} \geq y_{i j} \quad \forall i=1, \ldots, m \\
& \sum_{j=1} \lambda_{j} y_{i j} \leq y_{i j} \quad \forall i=m+1, \ldots, M \\
\lambda_{j} \geq 0 \quad \forall j=1, \ldots, s
\end{array} .
$$


The main difference from the FKHM model to the conventional BoD model is that (2.7) maximizes the difference between the weighted average of forward sub-indicators and the weighted average of reverse sub-indicators. Additionally, the presence of forward sub-indicators does not imply the presence of reverse ones and the model FKHM can reduce to the formulation of the conventional BoD model (2.4) when there are no reverse indicators [14].

The sub-indicators share restriction (2.6) was added to the FKHM formulation to prevent the model from assigning zero weights to some sub-indicators, since zero weight means that the sub-indicator associated has no influence in the global performance. 



\section{Chapter 3}

\section{Application and analysis of the BoD model}

In this chapter, examples with a small number of units and sub-indicators are used to better understand the BoD model and to evaluate the best options to deal with the anti-isotonic subindicators.

\subsection{Application of the BoD}

To better understand the conventional BoD model (2.4) and the need to include sub-indicator share restriction (2.6), previously introduced in Chapter 2, the CI analysis was performed for a small number of units and sub-indicators. In order to make this example illustrative, only two sub-indicators (Sub-indicator 1 and Sub-indicator 2) were used, making it possible to use graphic displays to clarify the outputs of the methodology. It is important to notice that both sub-indicators have positive effects on the performance, i.e. a higher scores imply a better performance. The data used for six units (A to F) is presented in Table 3.1.

Table 3.1: Example 1.

\begin{tabular}{|c|c|c|}
\hline \hline & Sub-indicator 1 & Sub-indicator 2 \\
\hline \hline A & 22.30 & 9.71 \\
\hline B & 15.70 & 1.18 \\
\hline C & 26.70 & 6.57 \\
\hline D & 15.80 & 18.81 \\
\hline E & 30.00 & 7.62 \\
\hline F & 11.50 & 7.91 \\
\hline \hline
\end{tabular}

The composite indicators were calculated through the model (2.4) using the Solver tool on Excel. The weights for the sub-indicators and the resulting CI values for each unit are presented 
in Table 3.2. The weight associated with Sub-indicator $1\left(y_{1}\right)$ is given by $w_{1}$ and the weight associated with Sub-indicator $2\left(y_{2}\right)$ is given by $w_{2}$.

The CI value for each unit is obtained by the sum of the product of each sub-indicator by its respective weight as $C I=w_{1} y_{1}+w_{2} y_{2}$.

Table 3.2: Weights and CI's results.

\begin{tabular}{|l|l|l|l|}
\hline \hline & $\boldsymbol{w}_{1}$ & $\boldsymbol{w}_{\mathbf{2}}$ & $\mathbf{C I}$ \\
\hline \hline $\mathbf{A}$ & 0.025 & 0.032 & $\mathbf{0 . 8 7 3}$ \\
\hline $\mathbf{B}$ & 0.033 & 0.000 & $\mathbf{0 . 5 2 3}$ \\
\hline $\mathbf{C}$ & 0.033 & 0.000 & $\mathbf{0 . 8 9 0}$ \\
\hline $\mathbf{D}$ & 0.000 & 0.053 & $\mathbf{1 . 0 0 0}$ \\
\hline $\mathbf{E}$ & 0.033 & 0.000 & $\mathbf{1 . 0 0 0}$ \\
\hline $\mathbf{F}$ & 0.025 & 0.032 & $\mathbf{0 . 5 4 3}$ \\
\hline \hline
\end{tabular}

Applying the BoD model, the units D and E have CI scores equal to one, being considered efficient. By plotting the sub-indicators data in a graphic representation, as shown in Figure 3.1, the frontier (in red) is easily identified and is formed by units D and E, which are the best performing units regarding the sub-indicators selected, corroborating with the results obtained by the model shown in Table 3.2.

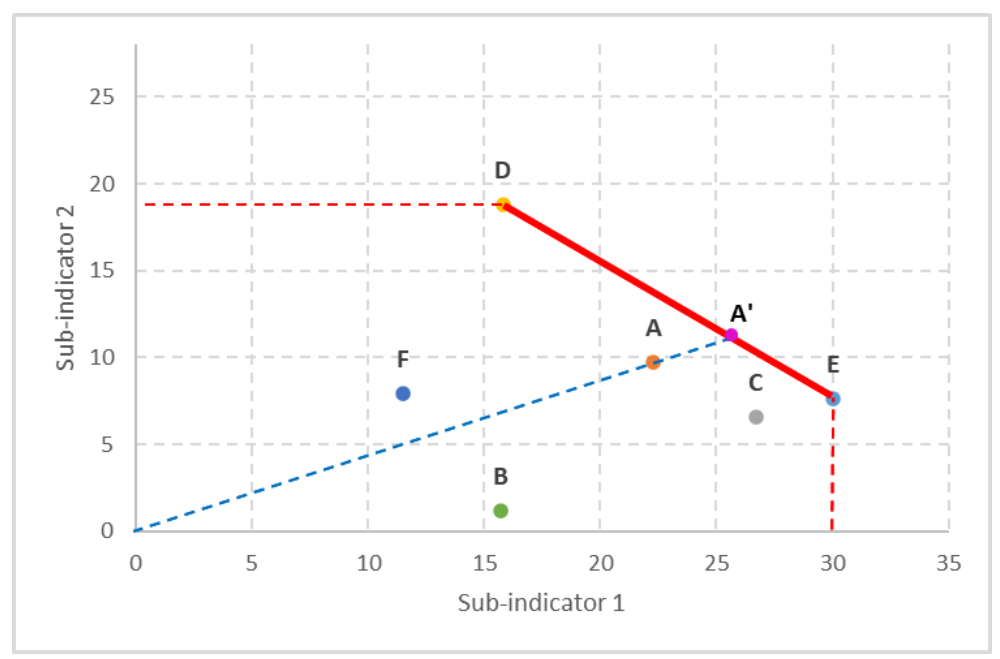

Figure 3.1: Efficiency Frontier.

The frontier is then used as reference to measure the relative performance of the other units, 


\subsection{Application of the $B o D$}

the inefficient ones. Through Figure 3.1 it is possible to calculate the $\mathrm{CI}$ as the ratio of the distance between the origin $(\mathrm{O})$ and the observed point $(\mathrm{A})$ and between the origin $(\mathrm{O})$ and the projected point (A') in the frontier which is represented in (3.1) [16]. In the example, as shown in Figure 3.1, the relative performance of the unit was determined using its observed values (22.3, 9.707) and the values of the projected point identified in the figure as OA' $(25.5,11.25)$.

$$
\frac{\mathrm{OA}}{\mathrm{OA}^{\prime}}=\frac{\sqrt{22.3^{2}+9.707^{2}}}{\sqrt{25.5^{2}+11.25^{2}}}=0.873
$$

As expected for the inefficient units, when analysing Table 3.2 and Figure 3.1, the units closer to the frontier, $\mathrm{A}$ and $\mathrm{C}$, have higher $\mathrm{CI}$ scores than the ones far from it, i.e., $\mathrm{B}$ and $\mathrm{F}$.

In this example, units $\mathrm{B}, \mathrm{C}$ and $\mathrm{E}$ assigned zero weight to Sub-indicator $2, w_{2}=0$, and unit $\mathrm{D}$ assigned zero weight to Sub-indicator $1, w_{1}=0$. As explained in Chapter 2, this is not desirable as the sub-indicator associated to this weight would have no influence in the final CI result. Using the additional restriction presented in (2.6), it is required that the sub-indicators share have a minimum contribution of $5 \%$, that is, $\alpha=0.05$. The updated weights and $\mathrm{CI}$ are presented in Table 3.3.

Table 3.3: Weights and CI's results using model 2.4 with additional sub-indicator share restriction (2.6).

\begin{tabular}{|l|l|l|l|}
\hline \hline & $\boldsymbol{w}_{\mathbf{1}}$ & $\boldsymbol{w}_{\mathbf{2}}$ & $\mathrm{CI}$ \\
\hline \hline $\mathrm{A}$ & 0.025 & 0.032 & $\mathbf{0 . 8 7 3}$ \\
\hline $\mathrm{B}$ & 0.028 & 0.020 & $\mathbf{0 . 4 6 8}$ \\
\hline $\mathrm{C}$ & 0.032 & 0.007 & $\mathbf{0 . 8 9 0}$ \\
\hline $\mathrm{D}$ & 0.003 & 0.051 & $\mathbf{1 . 0 0 0}$ \\
\hline $\mathrm{E}$ & 0.032 & 0.007 & $\mathbf{1 . 0 0 0}$ \\
\hline $\mathrm{F}$ & 0.025 & 0.032 & $\mathbf{0 . 5 4 3}$ \\
\hline \hline
\end{tabular}

As expected, all the weights assigned are greater than zero. The units that already have both weights greater than zero, i.e., A and F, have no change in their CI score, as these sub-indicators share satisfy the additional restriction (2.6). Even with this restriction imposed, units D and $\mathrm{E}$ remain the efficient ones. Units B and C, however, have lower CI values, since, before the sub-indicators share restrictions, both units use only sub-indicator 2 to derive their CI results. 
Unit B have a decrease of $11.6 \%$ in the CI result, as its performance on Sub-indicator 2 is much lower than the other units while unit $\mathrm{C}$ have a decrease of $0.16 \%$.

\subsection{Analysis of the transformation techniques for anti-isotonic sub-indicators}

To compare the different transformation techniques for dealing with anti-isotonic sub-indicators in the $\mathrm{BoD}$ model, a small example is applied: the $\mathrm{CI}$ is calculated for a small number of units and sub-indicators using the conventional BoD model (2.4) and the variant BoD model proposed by Fare et al. [14] (FKHM) presented in (2.7). However, Sub-indicator 2 is now considered an anti-isotonic sub-indicator, i.e., a sub-indicator which its increasing behaviour is not desirable to the desired performance. The data used is presented in Table 3.4 along with the units rank in each sub-indicator based on its score. The highest (blue) and lowest (red) values are highlighted for each sub-indicator.

Table 3.4: Example 2.

\begin{tabular}{|c||c|c||c|c|}
\hline \hline & $\begin{array}{c}\text { Sub-Indicator 1 } \\
\left(y_{1}\right)\end{array}$ & Rank & $\begin{array}{c}\text { Sub-indicator 2 } \\
\left(y_{2}\right)\end{array}$ & Rank \\
\hline \hline A & 22.30 & 6 & 92.20 & 7 \\
\hline B & 15.70 & 8 & 77.20 & 5 \\
\hline C & 29.70 & 4 & 85.70 & 6 \\
\hline D & 15.80 & 7 & 97.50 & 8 \\
\hline E & 32.40 & 3 & 47.60 & 4 \\
\hline F & 14.40 & 9 & 102.70 & 9 \\
\hline G & 33.70 & 1 & 103.10 & 10 \\
\hline H & 14.00 & 10 & 67.00 & 2 \\
\hline I & 32.90 & 2 & 71.40 & 3 \\
\hline J & 29.03 & 5 & 63.00 & 1 \\
\hline \hline
\end{tabular}

The CI was computed using the software R Studio and the Composite Indicators package Compind. This package contains various functions for the construction of composite indicators, 
including a function for the Benefit of the Doubt model and the BoD model with sub-indicators share restrictions that were used in this work. Each anti-isotonic sub-indicator transformation was applied previously on the database in the $c s v$ files. The function returns the estimated CI values and the weights assigned to the sub-indicators.

The Compind package did not have a function that implemented the FKHM model. Therefore, it was necessary to make alterations on the convention $\mathrm{BoD}$ model function in order to incorporate the subtraction of the weighted average of the reverse sub-indicators present in the FKHM model. The modified algorithm is presented in the Appendix B.

Figure 3.2 presents the results obtained with the different transformation techniques: Figure 3.2a shows the $\mathrm{CI}$ results obtained using the conventional $\mathrm{BoD}$ model with the inversion of the anti-isotonic sub-indicator (Inversion); Figure 3.2b shows the CI results for the conventional BoD model with the maximum-minimum technique (MM), setting the maximum value as $y_{\max }=105.1$ and minimum as $y_{\min }=61$; Figure $3.2 \mathrm{c}$ shows the conventional BoD model CI results of subtracting Sub-indicator 2 from a sufficiently large constant (Constant), achieving $\mathrm{K}-y_{2}$, being chosen the constant value $\mathrm{K}=110$; and finally, Figure $3.2 \mathrm{~d}$ shows the $\mathrm{CI}$ results of the FKHM model that includes Sub-indicator 2 as a reverse sub-indicator.

Table 3.5 shows the CI results obtained for each unit (A to J) when applying the BoD model with different transformation techniques for the anti-isotonic sub-indicator (Inversion, MM and Constant) and the FKHM model. The units' performances are ranked from highest to lowest for each technique, with the highest $\mathrm{CI}$ coloured in blue and the lowest in red.

The different transformation techniques for dealing with the anti-isotonic sub-indicator clearly generate different results. In general, the CI values are higher when using the Inversion technique and lower when using the FKHM model. The standard deviation is lower when using the Inversion technique and higher with the FKHM model.

The MM and the Constant techniques have very similar CI values, as they use similar approaches in the transformation of the anti-isotonic sub-indicator: subtracting it from a constant. The main difference is that in the MM technique also performs the normalization, by dividing each subtraction results by $y_{\max }-y_{\min }$. However, as previously mentioned, the normalization step is redundant in DEA models and does not change the CI results. Therefore, if the same 


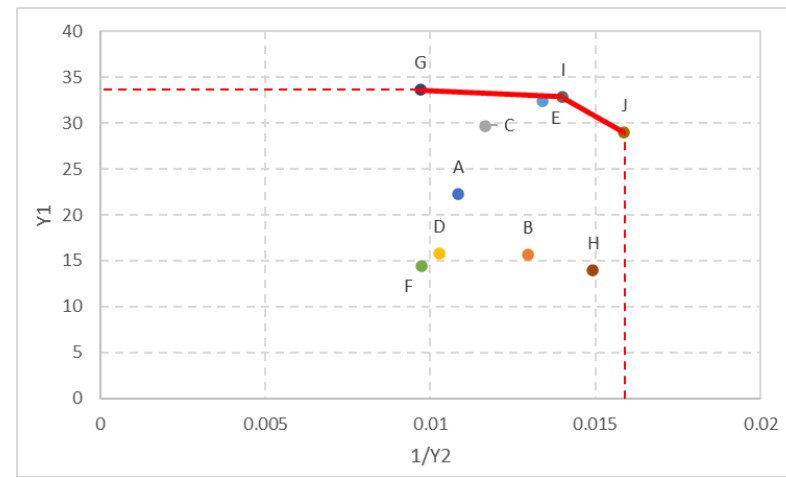

(a) Inverting Sub-indicator 2 .

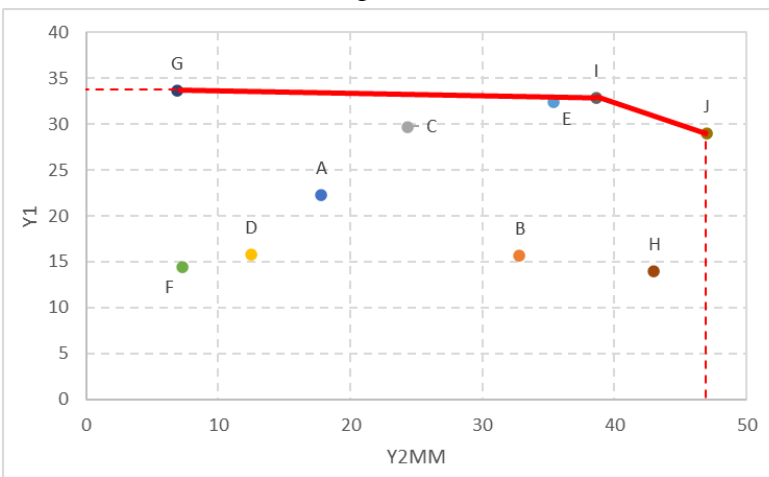

(c) Subtracting Sub-indicator 2 from a constant K.

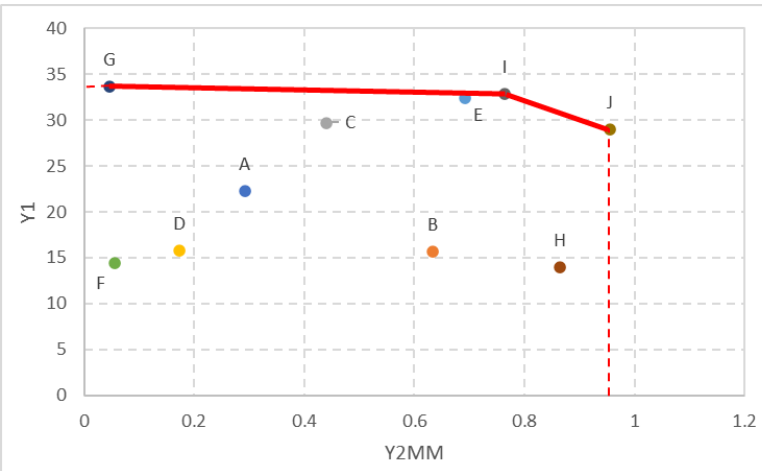

(b) Applying the MM technique.

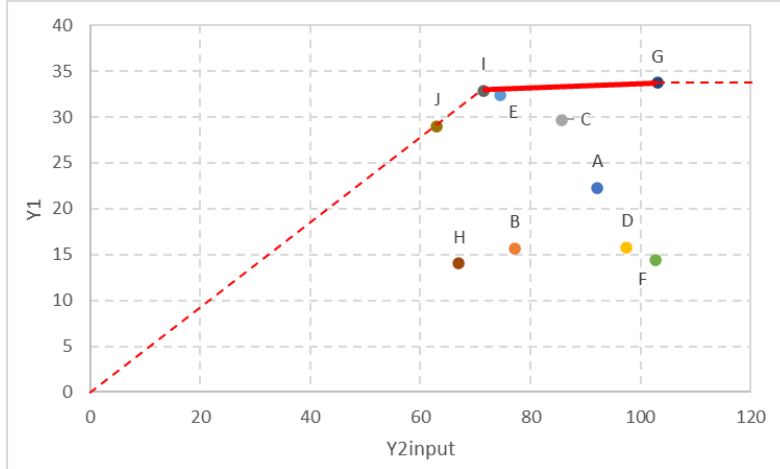

(d) Using the FKHM model.

Figure 3.2: Results from the different transformation techniques for the anti-isotonic sub-indicators.

value is chosen for the constant $\mathrm{K}$ and the maximum value $y_{\max }$ in the $\mathrm{MM}$ technique, the CI results would be the same.

The CI results ranking is similar in the first three techniques. Units $\mathrm{G}$ and I are efficient in all four techniques, and unit $\mathrm{J}$ is efficient in all except in the FKHM model. Unit $\mathrm{F}$ is the worst performing unit by using the Inversion, MM and Constant techniques, while it has the same rank position (8th) when using the FKHM model. The worst performing unit in the FKHM model is unit $\mathrm{H}$.

Globally, the main differences among the rankings achieved in the four approaches are related with units $\mathrm{H}$ and $\mathrm{J}$. The unit $\mathrm{H}$ has the worst performance in the forward sub-indicator, implying that it should not belong to the best practice frontier. The only approach which reflects this output is the FKHM model. It is interesting to observe that unit $\mathrm{G}$ has the best ranking in the forward sub-indicator 1 and it has the worst ranking in the reverse sub-indicator 2, and it is efficient in all approaches, including the FKHM model. This output occurs because unit $\mathrm{G}$ has the best ranking 
Table 3.5: CI's results with different transformation techniques for the anti-isotonic sub-indicator.

\begin{tabular}{|c||c|c||c|c||c|c||c|c|}
\hline \hline & Inversion & Rank & MM & Rank & Constant & Rank & FKHM & Rank \\
\hline \hline A & 0.723 & 6 & 0.670 & 5 & 0.672 & 6 & 0.662 & 5 \\
\hline B & 0.816 & 5 & 0.663 & 6 & 0.698 & 5 & 0.466 & 7 \\
\hline C & 0.898 & 4 & 0.895 & 4 & 0.895 & 4 & 0.886 & 3 \\
\hline D & 0.646 & 7 & 0.474 & 7 & 0.476 & 7 & 0.469 & 6 \\
\hline E & 0.983 & 2 & 0.983 & 2 & 0.983 & 2 & 0.981 & 2 \\
\hline F & 0.613 & 8 & 0.428 & 8 & 0.431 & 8 & 0.427 & 8 \\
\hline G & 1.000 & 1 & 1.000 & 1 & 1.000 & 1 & 1.000 & 1 \\
\hline H & 0.940 & 3 & 0.905 & 3 & 0.915 & 3 & 0.415 & 9 \\
\hline I & 1.000 & 1 & 1.000 & 1 & 1.000 & 1 & 1.000 & 1 \\
\hline J & 1.000 & 1 & 1.000 & 1 & 1.000 & 1 & 0.882 & 4 \\
\hline \hline Mean & 0.862 & \multicolumn{2}{|c||}{0.802} & 0.807 & 0.719 \\
\hline Std. Dev & 0.145 & \multicolumn{1}{|c|}{0.213} & 0.211 & 0.243 \\
\hline \hline
\end{tabular}

regarding the sub-indicator 1 and, by default, it is compared with itself and does not matter what happens with the other sub-indicators. Other situation is unit $\mathrm{J}$, which has the best ranking in the reverse sub-indicator 2 while ranking near the median position in the forward sub-indicator 1. Unit $\mathrm{J}$ is efficient in all approaches except in the FKHM model where it is assessed with CI $=0.882$. These results show that the FKHM model, when compared to the other techniques, rewards more the units that have a good performance in the forward sub-indicator than in the reverse sub-indicator and penalize more those that had higher values in the reverse sub-indicator.

Considering these arguments and the advantage of the FKHM model, which does not require the use of transformation techniques to adequate the anti-isotonic sub-indicators to the model, it is chosen to assess the EU countries environmental performance. Besides, considering the novelty of this model, since it has been just recently proposed, the present research will be one of the first studies using this model in the literature and the results in a different subject from the original application will be relevant [14].

With the objective of comparing the results achieved with the FKHM model, a transformation technique is also adopted to derive the environmental performance using the $\mathrm{BoD}$ model. The 
approach that performed closer to the FKHM model results. Even though, both MM and the Constant techniques have performances closer to the FKHM model, the Constant technique is chosen as it does not have the normalization step that would be redundant in a DEA model application. 


\section{Chapter 4}

\section{Indicators to assess transport}

\section{environmental performance}

This chapter presents a research on relevant literature of environmental transport assessment and on the use of transport sustainability sub-indicators. The methodology for the selection of sub-indicators is shown along with the sub-indicators selected for this work.

\subsection{Transport sustainable development}

There are many definitions in the literature about sustainability. Sometimes it is defined only in terms of environmental sustainability, related more with pollution reduction and habitat preservation [30]. The term is usually related to the 1987's Brundtland report [31], in which sustainable development was defined as: "development that meets the needs of the present without compromising the ability of future generations to meet their own needs". This definition has been increasingly broadening to include other goals and many experts use the definition that sustainability balances economic, social and environmental goals [30]. This was called the triple bottom line and was introduced by Elkington in 1994 [32]. Table 4.1 shows the goals for each category. Although they are separately classified here, the goals often overlap various categories.

The transport sustainability can be also defined by these three categories (economic, social and environmental). The economic category is related to making transport affordable, efficient, with mode options and able to support a competitive economy [30], [33]. In the social sphere, sustainable transport must allow basic access of individuals to be met safely and in a way that supports equity within and between generations. In the environmental dimension, sustainable transport is the one that limits emissions and waste within the planet's ability to 
Table 4.1: Sustainability goals - triple bottom line. Source: Adapted from [30].

\begin{tabular}{|c|c|c|}
\hline \hline Economic & Social & Environmental \\
\hline \hline Economic productivity & Equity & $\begin{array}{c}\text { Climate change } \\
\text { mitigation }\end{array}$ \\
\hline Economic development & Safety and security & $\begin{array}{c}\text { Prevention of air, noise } \\
\text { and water pollution }\end{array}$ \\
\hline Resource efficiency & $\begin{array}{c}\text { Community } \\
\text { development }\end{array}$ & $\begin{array}{c}\text { Non-renewable } \\
\text { resource conservation }\end{array}$ \\
\hline Affordability & $\begin{array}{c}\text { Cultural heritage } \\
\text { preservation }\end{array}$ & $\begin{array}{c}\text { Open space } \\
\text { preservation }\end{array}$ \\
\hline Operational efficiency & $\begin{array}{c}\text { Public fitness and } \\
\text { health }\end{array}$ & Biodiversity protection \\
\hline \hline
\end{tabular}

absorb them, increases the use of renewable resources while gradually substitutes non-renewable ones, minimizing the impact on land and the generation of noise.

According to [11], the definition of transport sustainability is usually more focused in the context of decision making to achieve sustainable transport in opposition to a simple representation of a subject. Therefore, the sub-indicators to be used need to adress the information that is relevant to the performance of policies.

The following overviews summarizes some literature on sustainable performance assessment using diverse methods of normalization, weighting and aggregation.

H. Gudmundsson and M. B. Regmi [9] develop a Sustainable Urban Transport Index to monitor and measure the sustainable urban transport progress towards the Sustainable Development Goals for cities in the Asian-Pacific region. They describe in detail the framework definition and sub-indicators choice. The index is settled with four objectives: it should reflect the Sustainable Development Goals and other sustainability concerns, the number of sub-indicators should be limited to the few most essential ones, hard to collect or overly demanding sub-indicators should be avoided and the index method should be simple, unbiased and transparent. With this, ten sub-indicators were selected more focused on public transport investments, access and quality. The sub-indicators were normalized using the maximum-minimum method and were aggregated by a geometric mean with each sub-indicator having an equal weight of 0.10 . 
Considering that choices in normalization, weighting and aggregations techniques significantly affect the composite indicator, the authors in [13] made a comparison of 33 different combinations of these techniques. A set of 16 sub-indicators was selected to estimate the composite indicator of sustainable urban mobility for Italian provincial towns. The weighting options tested in this work were equal weighting, the use of literature-based weights (as expert information was not available) and PCA/FA technique. The weighted and normalized sub-indicators were then aggregated through three different methods: linear, geometric and concave rules.

The work performed in [33] evaluates the sustainability of passenger transport in 23 Spanish cities by creating a composite indicator. The sub-indicators were normalized using the standardised values method and then aggregated into composite indicators related to each dimensions of sustainability: social, environmental or economic. Equal weights of one were assigned to the sub-indicators with the sign of the each weight depending on the meaning of the sub-indicator, positive for sub-indicators in which an increase in their values contributes to a more sustainable transport system and negative for those contributing conversely. The sub-indicators were aggregated into these three $\mathrm{CI}$ through a simple average calculation. To calculate the global sustainability $\mathrm{CI}$, the weights were obtained in the literature of previous decision makers, company representatives and researchers opinions. It was attributed a weight of 0.289 for the economic dimension, 0.357 for the social dimension and 0.354 for the environmental dimension.

A composite indicator for transport sustainability in Melbourne local areas was developed in [12] to compare different planning scenarios. Nine sub-indicators were chosen to consider the environmental, social and economic performance, and were normalized by the maximumminimum method. The sub-indicators were first aggregated into environmental, social and economic sub-indexes using PCA/FA and then combined into a single CI.

In [34], a set of 24 sub-indicators, within six areas defined as budget, planning and land-use, safety, time, health and environment and social, was selected to build the Normalized Transport Sustainability Index. The index was build to evaluate the sustainability of urban areas of 36 European cities. The sub-indicators were normalized in a range between 0 and 1 using the maximum-minimum method and the index was calculated using the Euclidean distance between the city evaluated and an hypothetical worst city. This hypothetical worst city assumes the value 
of one or zero depending on the effect of the sub-indicator. When the effect is negative it assumes the value of one and if the effect is positive its value is equal to zero.

A literature example of the assessment of transport sustainability in countries instead of cities was presented in [35]. In this work a CI was constructed to assess the performance of 112 countries related to green transportation and logistics practices. The composite indicator combines the logistic performance index, the $\mathrm{CO}_{2}$ emissions and the oil consumption values from transport using the DEA for weighting and aggregation.

Another work performed by A. Dobranskyte-Niskota, A. Perujo, and M. Pregl [1], measures and assesses the transport activities sustainability performance of the EU-27 using 32 subindicators. A set of 55 transport sustainability sub-indicators was considered and analysed and the sub-indicators were selected based on their availability, reliability and completeness. The subindicators were aggregated into the SusTrans Index using an equal weight aggregation method. This report also presents a graphic interface that was designed to compare the sub-indicators groups, communicate quick impressions and point areas of success and problems.

Some of the most common sub-indicators found in literature are listed in Table 4.2.

Table 4.2: Sustainability sub-indicators found in literature.

\begin{tabular}{|c|c|}
\hline \hline Sub-indicator & Sources \\
\hline \hline Air pollution & {$[13],[12],[34],[36]$} \\
\hline Traffic fatalities & {$[9],[13],[33],[12],[34]$,} \\
& {$[36]$} \\
\hline Affordability of transport & {$[9],[13],[33],[12],[34]$} \\
\hline Access to public transport & {$[9],[13],[12]$,} \\
\hline Energy consumption per car & {$[13],[33],[34]$} \\
\hline Time spent on mobility & {$[13],[33],[34]$} \\
\hline Land consumption for transport & {$[33],[12]$} \\
\hline \hline
\end{tabular}




\subsection{Data and variables}

As the CI consists on the aggregation of several sub-indicators, their selection is of crucial importance to compute the overall performance. The proposed composite indicator is developed with the intention to achieve a balance between what is necessary to support a sustainable transport assessment and the available data for EU countries.

Based on the literature review of previous works with similar concepts on sustainable transport and sub-indicators, several sub-indicators were considered that incorporate important topics related to the EU's White Paper (Roadmap) [7] and the Sustainable Development Goals [8]. For the first filtering of the sub-indicators it was taken into consideration that each sub-indicator should be of easy interpretation and measure a specific area of the performance, ensuring the minimum number of sub-indicators that assures that all dimensions are reflected in the calculation of CI. Besides, it also needed to be taken into consideration the data availability for all the EU countries during the time span under analysis.

Taken into account these topics, nine sub-indicators were initially considered to measure the environmental performance, four forward sub-indicators (i.e., capturing positive aspects) and five reverse sub-indicators (i.e., capturing negative aspects). The forward sub-indicators are the share of buses and trains in total passengers transport, the share of energy from renewable sources in transport, the share of rail and inland waterways in total freight transport and the environmental transport taxes. The reverse sub-indicators are people dead in road accidents, GHG emissions by fuel combustion in transport, the average $\mathrm{CO}_{2}$ emissions per kilometer from new passengers cars, the energy dependency on oil and petroleum products and the share of people that suffer from noise. These sub-indicators are described hereinafter.

The share of buses and trains in total passengers' transport (public transport) is expressed in percentage and measures the share of passenger's transport made by collective transport in the total inland transport. Collective transport refers to buses (including coaches and trolley-buses) and trains, while the total inland transport (denominator) includes these facilities and also the numbers for passenger cars transport. Trams and metros are not included due to the lack of harmonised data. The passengers' transport data is measured in passenger-kilometer (pkm), a 
unit that represents the transport of one passenger over one kilometer using a specific mode of transport. The public transport sub-indicator is related to two Sustainable Development Goals related to industry, innovation and infrastructure, which highlights the importance of building resilient and sustainable infrastructure. On the other hand, the Sustainable Development Goal in which it is highlighted the importance of building resilient and sustainable infrastructure and the necessity to renew and plan cities so they offer access to basic services for all. This sub-indicator also relates to the necessity of improving the transport quality, accessibility and reliability, as discussed in the Roadmap.

The share of energy from renewable sources in transport (renewable energy) is expressed as the percentage of renewable energy in the total transport fuels. Energy by renewable sources consumed in transport is given by the sum of sustainable biofuels, renewable electricity, hydrogen and synthetic fuels of renewable origin and other reported forms of renewable energy such as geothermal, solar thermal, renewable municipal waste and solid biofuels [37]. In the denominator, the total transport fuels, is given by the petrol and diesel quantities, as well as the total biofuel and electricity numbers. The energy data is collected in fuel specific units and converted to the common energy units, kilo tonnes of oil equivalent (ktoe), to allow the calculations. With this sub-indicator it is possible to understand how extensive is the use of renewable energy in the transport sector and how much it has been replacing fossil fuels. The Renewable Energy Directive promotes policies for the production and promotion of energy from renewable sources in the $\mathrm{EU}$, and in their 2009 original directive sets a $10 \%$ target for renewable energy in transport for 2020 [38]. In the revised version from 2018, a new target of $32 \%$ for 2030 was established [39]. A higher share of renewable energy in the transport sector can contributes to a significant reduction in the GHG emissions, and also reduces the local air and noise pollution. The Roadmap also suggests a regular phase out of conventionally-fuelled vehicles from urban environments by halving their number in 2030 and phasing them out of the cities by 2050 .

The share of rail and inland waterways in total freight transport (freight transport) is expressed in percentage of the total inland transport which includes freight on national territory made by road, rail and inland waterways transport. Sea and air freight transport are not represented in the sub-indicator. The freight transport is expressed in tonne-kilometer (tkm), a unit that 
represents the transport of one tonne over one kilometer by a specific transport mode. Denmark, Estonia, Ireland, Greece, Latvia, Portugal, Slovenia, Sweden did not present values of freight transport by inland waterways. Therefore, in these countries only the values of rail transport were considered. Cyprus and Malta did not present values neither for railways nor inland waterways and, consequently, the freight transport sub-indicator was not applied to them. As an effort to have a complete database without excluding these countries from the evaluation in this work the lowest values observed on the dataset were used for Cyprus and Malta for every year of the time span. This method, suggested by Morais et al. [40], avoids that these countries become unintended benchmarks, and therefore, it will not affect the location of the best practice frontier. Freight transport is an essential part of the European internal market. As highlighted in the Roadmap, it needs to be kept free to maintain EU industry and services competitiveness, while still be organized in an environmentally sustainable way. The Roadmap also mentions the objective of shifting $30 \%$ of the road freight to other modes, such as rail and waterways, by 2030 and more than $50 \%$ by 2050 . This sub-indicator also reflects the progress toward the Sustainable Development Goals focused on innovation and on building resilient and sustainable infrastructure.

The environmental transport taxes sub-indicator (environmental taxes) measures the environmental taxes revenue related to the transport economic activities. This sub-indicator includes mainly the revenue from taxes related to the ownership and use of motor vehicles, but also includes taxes from other transport equipment and services. The sub-indicator does not include the environmental taxes from fuel for transport, as these are included under energy taxes. The original sub-indicator values are in million euros, thus it was normalized using the country's population on 1st January of each year, to consider the dimension of the country. Therefore, the unit of measure is million euros per hundred thousand inhabitants. If a high tax collection is viewed as a reflect of a strong environmental policy, this can be considered a positive sub-indicator. On the other hand, if it is viewed that a country has high environmental tax collection due to high levels of environmental pollution, this can be seen as an negative sub-indicator. The Roadmap highlights the necessity of moving towards a full application of the polluter-payer principle to eliminate distortions and harmful subsidies. Therefore, the information on environmental taxes 
is relevant to policy analyses and to introduce changes in the environmental fiscal policy.

The people dead on road accidents (road deaths) sub-indicator measures the number of fatalities in road accidents per hundred thousand inhabitants. This sub-indicator includes passengers and drives of motorized vehicles and pedal cycles, as well as pedestrians, that have died up to 30 days after the accident. The average population of the reference year (used as denominator) is calculated as the arithmetic mean of the population on 1st January of two consecutive years. This sub-indicator is aligned with two Sustainable Development Goals aiming at safer cities and health and well-being status. The European Commission aims to make EU a world leader in safety and security of all modes of transport. As highlighted in the Roadmap, EU aims to reduce fatalities close to zero by 2050 with initiatives in the areas of technology, enforcement and education.

The GHG emissions by fuel combustion in transport (GHG emissions) measures the transport's fuel combustion contribution in the total greenhouse gas emissions inventory. This includes the emissions of carbon dioxide $\left(\mathrm{CO}_{2}\right)$, methane $\left(\mathrm{CH}_{4}\right)$, nitrous oxide $\left(\mathrm{N}_{2} \mathrm{O}\right)$, perfluorocarbons (PFCs), hydrofluorocarbons (HFCs), sulphur hexafluoride $\left(\mathrm{SF}_{6}\right)$ and nitrogen trifluoride $\left(\mathrm{NF}_{3}\right)$. The values are originally expressed in thousand tonnes and were normalized using the countries' population on 1st January of each year, to take into consideration their dimension. Therefore, the sub-indicator's data is expressed in thousand tonnes per hundred thousand inhabitants for each country. The GHG emissions from the transport by road and inland waterways accounted for $22 \%$ of the total European Union emissions in 2017 and reached 27\% when including international aviation and maritime emissions [5]. The Roadmap sets out a target of $60 \%$ reduction in the GHG emissions by 2050 compared to 1990 levels.

The average carbon dioxide $\left(\mathrm{CO}_{2}\right)$ emissions per kilometer from new passengers' cars (new car emissions) is defined as the average $\mathrm{CO}_{2}$ emissions per kilometer in a given year for new passenger cars and expressed in grams of $\mathrm{CO}_{2}$ per kilometer. This is a target for the average of the manufacturer's overall fleet, meaning that cars above the limit are allowed in the market as long as they are offset by the production of lighter cars. To determine the vehicle emissions, each car follows a predefined driving cycle of acceleration, gear changes, steady speeds and deceleration performed by a trained driver. During this process all the emissions from the 
vehicle tailpipe are collected and subsequently analysed. The Regulation (EU) 2019/631 sets a mandatory target for emission reduction for new cars of 95 grams of $\mathrm{CO}_{2}$ per kilometer by 2021 [41]. This sub-indicator reflects the Sustainable Development Goals related to ensuring sustainable and environmentally aware consumption and production patterns, to the innovation in search of lasting solutions to environmental challenges and the call for climate action. The Roadmap also highlights the importance of the research and innovation on vehicle propulsion technologies and the improvement of energy efficiency performance of vehicles across all modes.

The energy dependency on oil and petroleum products (energy dependency) sub-indicator monitors to which extent the countries economy relies on imports of oil and petroleum products to meet its energy needs. It is calculated by dividing the net imports by the gross available energy and it is used in a percentage basis. The net imports are the difference between the total imports and the total exports. The gross available energy is the sum of primary products, recovered and recycled products and imports minus the sum of exports and stock changes. The oil and petroleum products values do not include the biofuel portion. Regarding its metrics, the energy dependency sub-indicator value may be higher than $100 \%$ with regard to countries creating a stock in a given year or it can be negative, for oil exporter countries. A negative value occurred only once in the dataset, and the value was close to zero $(-4.701 \%)$ for the exporter country. To maintain the relative position of all units regarding the other countries, a constant $\mathrm{K}$ of $5.701 \%$ was added. This way the best score of $1 \%$ is assigned to the exporter country, avoiding the necessity of handling negative data in the model and the relative position of the units are kept the same. This sub-indicator shows the EU countries progress toward more resource efficient policies. As oil becomes scarcer each year, the necessity of reducing EU dependency on oil imports, without reducing the transport system efficiency, is one of the objectives mentioned in the Roadmap. Imports exposes the economy to volatile world market prices and the risk of supply shortages.

The share of people living in households that suffer from noise was also examined to be an sub-indicator for measuring the environmental performance. This sub-indicator measures the percentage of the population that declares to be affected by noise from the street or from the neighbours. It is associated with the Sustainable Development Goal related to making cities 
more inclusive, safe, resilient and sustainable, as well as the goal aiming for good health and well-being. The Roadmap also mentions noise exposure as a problem that need to be addressed, and the increase use of electric, hybrid and hydrogen cars would help to reduce the population exposure to this problem. However, the assessment for this sub-indicator is highly subjective and could reflect the level of noise pollution as well as people's perception of acceptable levels. An increase in the sub-indicator may only indicate a decrease of the population willingness to tolerate noise pollution. Since this is a subjective sub-indicator and people's opinions are not always consistent, it was opted not to use it in the CI.

The data on these sub-indicators for the 28 EU countries, from 2015 to 2018, was collected. The countries considered were Belgium, Bulgaria, Czechia, Denmark, Germany, Estonia, Ireland, Greece, Spain, France, Croatia, Italy, Cyprus, Latvia, Lithuania, Luxembourg, Hungary, Malta, Netherlands, Austria, Poland, Portugal, and Estonia, Slovenia, Slovakia, Finland, Sweden and United Kingdom. It was chosen to use the United Kingdom data, since during the time span of the assessment the country still integrated the European Union.

All the data used in this work was gathered from the Eurostat database [42] - the official statistical office of the EU. Since the publication of the Statistical Law (Regulation N223/2009), Eurostat is the statistical authority of the EU, coordinating the statistical activities of the institutions and ensuring the production of statistics according to established rules and principles. This database includes various European transport statistics of major transport modes and takes into account aspects such as infrastructure, transport equipment, economic performance of transport, role of transport in the employment, besides other issues such as passengers, goods and accidents [1].

\subsubsection{Correlation analysis}

Each sub-indicator included in the assessment needs to measure a unique dimension of the environmental performance of the transport sector. When two correlated sub-indicators are selected, an element of double counting can be introduced into the CI, which should be avoided. Thus, the correlation coefficient between each pair of sub-indicators is calculated. 
The correlation coefficient or Pearson coefficient $(r)$ is the most used method for measuring the linear dependence between two continuous variables. The correlation coefficient is computed as $r_{X Y}=\frac{s_{X Y}}{s_{X} s_{Y}}$, in which, $X$ and $Y$ are two sub-indicator's datasets and $s_{X Y}$ is the sample covariance of $X$ and $Y, S_{X}$ and $S_{Y}$ are the standard deviation of each variable $X$ and $Y$, respectively. Thus, the correlation coefficient has a dimensionless value ranging from $r=-1$ to $r=1$. An absolute value of $r$ equal to 1 represents a perfect linear correlation between the variables under analysis. The correlation direction is represented by the positive or negative sign of $r$. The positive sign designates a linear association varying in the same direction and the negative sign represents a linear correlation varying in the opposite direction. A correlation coefficient of zero means that the two sub-indicators do not associated linearly from each other [43].

The significance level of the correlation, or the $p$-value, was also determined. The $p$-value can be determined by first calculating the $t$-value as $t=\frac{r}{\sqrt{1-r^{2}}} \sqrt{n-2}$ and then using the student distribution table to find the corresponding $p$-value for the degrees of freedom $d f=n-2$, where $n$ is the number of observations. Considering a level of significance equal to $5 \%$, if the $p$-value is less than 0.05 , then the correlation between sub-indicators $X$ and $Y$ is statistical significant.

It is important to note that the correlation analysis is not a causality analysis. The correlation only indicates if the linear variation in the two data sets exists. It is a measure of closeness between two sets of observed data and sub-indicators should not be excluded solely based on their correlation levels, being necessary to complement this analysis with graphical analysis to identify non-linear relationship [16]. Sub-indicators such as GHG emissions, energy consumption, car ownership or transport accessibility tend to be correlated to each other. This happens as a result to the fact that they capture different aspects of the same subject [13]. Also, the Handbook on Composite Indicators [16] highlights that the weights should ideally reflect the contribution of each sub-indicator to the index. Therefore, the double counting of the sub-indicators should not only be determined by statistical analysis but also through an analysis of each individual sub-indicator in relation to the others and in relation to the overall phenomena they all aim to measure.

The $r$ and the $p$-value achieved between each pair of the eight sub-indicators described to 
derive the environmental performance assessment were obtained using the RStudio and the results are presented in Table 4.3. The correlation coefficients are shown on top of the cell and the p-values are shown in the bottom between parentheses. The values highlighted in red are the correlations that were deemed significant when considering a level of significance of $5 \%$.

Table 4.3: Sub-indicators correlation matrix and p-values.

\begin{tabular}{|c|c|c|c|c|c|c|c|c|}
\hline & $\begin{array}{l}\text { Public } \\
\text { transport }\end{array}$ & $\begin{array}{c}\text { Road } \\
\text { deaths }\end{array}$ & $\begin{array}{c}\text { Renewable } \\
\text { energy }\end{array}$ & $\begin{array}{c}\text { GHG } \\
\text { emission }\end{array}$ & $\begin{array}{l}\text { New car } \\
\text { emission }\end{array}$ & $\begin{array}{l}\text { Freight } \\
\text { transport }\end{array}$ & $\begin{array}{c}\text { Environ. } \\
\text { taxes }\end{array}$ & $\begin{array}{l}\text { Energy de- } \\
\text { pendency }\end{array}$ \\
\hline $\begin{array}{c}\text { Public } \\
\text { transport }\end{array}$ & & $\begin{array}{c}0.1310 \\
(0.1687)\end{array}$ & $\begin{array}{c}-0.0039 \\
(0.9671)\end{array}$ & $\begin{array}{c}-0.1031 \\
(0.2793)\end{array}$ & $\begin{array}{c}0.3153 \\
(0.0007)\end{array}$ & $\begin{array}{c}0.0080 \\
(0.9332)\end{array}$ & $\begin{array}{c}-0.1295 \\
(0.1737)\end{array}$ & $\begin{array}{c}0.0176 \\
(0.8536)\end{array}$ \\
\hline $\begin{array}{c}\text { Road } \\
\text { deaths }\end{array}$ & & & $\begin{array}{c}-0.3214 \\
(0.0006)\end{array}$ & $\begin{array}{c}-0.1410 \\
(0.1381)\end{array}$ & $\begin{array}{c}0.3055 \\
(0.0011)\end{array}$ & $\begin{array}{l}0.4430 \\
(1 \mathrm{E}-6)\end{array}$ & $\begin{array}{c}-0.5716 \\
(4.65 \mathrm{E}-11)\end{array}$ & $\begin{array}{c}0.1639 \\
(0.0843)\end{array}$ \\
\hline $\begin{array}{c}\text { Renewable } \\
\text { energy }\end{array}$ & & & & $\begin{array}{l}-0.0169 \\
(0.8599)\end{array}$ & $\begin{array}{l}-0.0104 \\
(0.9137)\end{array}$ & $\begin{array}{l}-0.0121 \\
(0.8994)\end{array}$ & $\begin{array}{c}0.2426 \\
(0.0100)\end{array}$ & $\begin{array}{c}0.0658 \\
(0.4904)\end{array}$ \\
\hline $\begin{array}{c}\text { GHG } \\
\text { emission }\end{array}$ & & & & & $\begin{array}{c}0.1440 \\
(0.1298)\end{array}$ & $\begin{array}{l}-0.1930 \\
(0.0415)\end{array}$ & $\begin{array}{c}0.0797 \\
(0.4033)\end{array}$ & $\begin{array}{c}0.0787 \\
(0.4092)\end{array}$ \\
\hline $\begin{array}{l}\text { New car } \\
\text { emission }\end{array}$ & & & & & & $\begin{array}{c}0.5074 \\
(1.13 \mathrm{E}-8)\end{array}$ & $\begin{array}{c}-0.5535 \\
(2.46 \mathrm{E}-10)\end{array}$ & $\begin{array}{c}0.2155 \\
(0.0225)\end{array}$ \\
\hline $\begin{array}{c}\text { Freight } \\
\text { transport }\end{array}$ & & & & & & & $\begin{array}{l}-0.3048 \\
(0.0011)\end{array}$ & $\begin{array}{c}0.1031 \\
(0.2792)\end{array}$ \\
\hline $\begin{array}{c}\text { Environ. } \\
\text { taxes }\end{array}$ & & & & & & & & $\begin{array}{c}-0.5000 \\
(1.99 \mathrm{E}-8)\end{array}$ \\
\hline $\begin{array}{l}\text { Energy de- } \\
\text { pendency }\end{array}$ & & & & & & & & \\
\hline
\end{tabular}

The environmental taxes sub-indicator obtained significant correlation with five of the other sub-indicators. A negative correlation factor was obtained in relation to the road deaths, the new car emissions, the freight transport and the energy dependency sub-indicators, of -0.5716 (4.65E-11), -0.5535 (2.46E-10), -0.3048 (0.0011) and -0.5000 (1.99E-8), respectively. And a significant positive correlation of $0.2426(0.0100)$ was observed between the environmental taxes sub-indicator and the renewable energy one.

Significant correlations were also found in the road deaths sub-indicator in relation to the renewable energy sub-indicator, the new car emissions sub-indicator and the freight transport, with correlation values of $-0.3214(0.0006), 0.3055$ (0.0011) and 0.4430 (1E-6), respectively. It should also be pointed out the correlation between the new car emissions sub-indicator and the public transport, the freight transport and the energy dependency sub-indicators, with positive correlations of $0.3153(0.0007), 0.5074(1.13 \mathrm{E}-8), 0.2155(0.0225)$, respectively.

The correlation coefficients obtained between the other pairs of sub-indicators were not 
significant.

In a broadly overview, the sub-indicator that presented higher and more significant correlation coefficients with the other sub-indicators was the environmental taxes. Since this sub-indicator reflects the taxes related to the transport emissions, and this dimension is already considered in the model, these results are coherent. As a result, and taking into account that this sub-indicator does not have an easy and direct interpretation, it was decided not to use it directly in the transport environmental performance index. Instead, it is used in a later stage to analyse if the countries' policies related to the transport environmental taxes are somehow adjusted to their overall transport environmental performance.

Table 4.4 summarizes the seven sub-indicators selected to calculate the transport environmental index, their units of measurement and their direction of interpretation, i.e. if the sub-indicator contributes positively or negatively to the country's transport environmental performance.

Table 4.4: Sub-indicators selected.

\begin{tabular}{|c|c|c|}
\hline \hline Sub-indicator & Unit of measurement & Direction \\
\hline \hline Public transport & Percentage (\%) & Forward \\
\hline Renewable energy & Percentage (\%) & Forward \\
\hline Freight transport & Percentage (\%) & Forward \\
\hline Road deaths & $\begin{array}{c}\text { Number of deaths per } \\
100 \text { thousand inhabitants }\end{array}$ & Reverse \\
\hline GHG emissions & $\begin{array}{c}\text { Thousand tonnes per } 100 \\
\text { thousand inhabitants }\end{array}$ & Reverse \\
\hline New car emissions & Grams per kilometer & Reverse \\
\hline Energy dependency & Percentage $(\%)$ & Reverse \\
\hline \hline
\end{tabular}





\section{Chapter 5}

\section{Results and discussions}

In this chapter, the data from the sub-indicators is presented and analysed. The composite indicator of transport environmental performance is obtained using the conventional BoD model, using the Constant linear transformation technique to transform the data of the anti-isotonic sub-indicators, and the variant BoD model proposed by Färe, et al. in [14] that does not require any transformation on the reverse sub-indicators.

\subsection{Descriptive analysis of the variables}

The transport environmental performance was assessed for the $28 \mathrm{EU}$ countries, from 2015 to 2018. As previously pointed out, the study considers the United Kingdom data, since during the time span of the assessment the country still integrated the European Union. Table 5.1 shows two descriptive statistics for the sub-indicators under analysis across countries for each year. The mean of the sub-indicators was calculated for each year, as well as the dispersion coefficient (DC). The DC measures the dispersion of the data around the mean and is given by the ratio between the standard deviation and the mean. It was calculated in order to facilitate the analysis among sub-indicators, since it allows the comparison of the degree of variation between different data sets even if they have different measurement units.

Analysing the forward sub-indicators in Table 5.1, it can be seen that, although the share of public transport in total passenger transport has been decreasing from 2015 until 2017, it increased in 2018, however still stayed more than 2\% bellow 2015 levels. The average share of renewable energy in transport presented the highest improvement: in 2018, it had increased more than $17 \%$ above 2015 values. The share of freight transport had a similar trajectory to the public transport sub-indicator and although the improvement on the last year in 2018, still kept 
Table 5.1: Mean and DC of the indicators data used in the construction of the CI.

\begin{tabular}{|c||c|c||c|c||c|c||c|c|}
\hline \hline \multicolumn{1}{|c||}{} & \multicolumn{2}{c||}{$\mathbf{2 0 1 5}$} & \multicolumn{2}{c||}{$\mathbf{2 0 1 6}$} & \multicolumn{2}{c||}{$\mathbf{2 0 1 7}$} & \multicolumn{2}{|c|}{$\mathbf{2 0 1 8}$} \\
\hline Sub-indicator & Mean & DC & Mean & DC & Mean & DC & Mean & DC \\
\hline \hline Public transport & 18.175 & 0.240 & 17.996 & 0.237 & 17.743 & 0.246 & 17.757 & 0.243 \\
\hline Renewable energy & 6.568 & 0.792 & 6.210 & 0.744 & 6.898 & 0.732 & 7.700 & 0.631 \\
\hline Freight transport & 27.964 & 0.732 & 26.975 & 0.728 & 26.929 & 0.724 & 27.054 & 0.722 \\
\hline Road deaths & 5.811 & 0.366 & 5.632 & 0.325 & 5.325 & 0.359 & 5.382 & 0.328 \\
\hline GHG emissions & 209.327 & 0.768 & 212.216 & 0.711 & 214.089 & 0.696 & 217.323 & 0.721 \\
\hline New car emissions & 120.946 & 0.078 & 118.757 & 0.066 & 119.168 & 0.064 & 120.457 & 0.067 \\
\hline Energy dependency & 98.482 & 0.232 & 96.470 & 0.233 & 95.450 & 0.243 & 95.500 & 0.209 \\
\hline \hline
\end{tabular}

\section{$3.26 \%$ bellow 2015 levels.}

Regarding the reverse sub-indicators, the average of road deaths for all countries, even though had a slight increase in the last year, has decreased more than $7 \%$ between 2015 and 2018. The average of GHG emissions for all countries has constantly increased and by 2018 was almost 4\% higher than 2015 levels. The average new car emissions has been increasing in the last two years but still remained $0.4 \%$ below 2015 levels. The average energy dependency of the EU countries decreased more than $3 \%$ between the years analysed.

The highest DC value, or data dispersion relative to the mean, was observed in the share of renewable energy in 2015, which translates the difference among countries in available renewable energy. Some countries, such as Finland in 2015, had 24.8\% of the fuel in transport from renewable sources while the average for the sub-indicator was of $6.54 \%$. However, the DC for this sub-indicator has been constantly decreasing and was $20 \%$ lower in 2018 when compared to 2015 , reflecting a tendency to increase the homogeneity among EU countries. Another high DC value was obtained by the GHG emissions sub-indicator, reflecting the different policies of EU countries for reducing emissions. For example, Luxembourg had 1013.489 thousand tonnes per hundred thousand inhabitants of GHG emissions in 2015, while Romania only had 79.080 thousand tonnes per hundred thousand inhabitants. The share of freight transport also had a high DC, since some countries have geographical locations and environmental conditions that facilitate the utilization of rail and inland waterways.

The lowest variability relative to the mean was observed for the average $\mathrm{CO}_{2}$ emissions per kilometer from new passengers cars. This can be reflecting a higher homogeneity EU regulations which have introducing $\mathrm{CO}_{2}$ emission performance standards for manufacturers operating in the 


\subsection{Descriptive analysis of the variables}

EU market (for instance, Regulation (EU) No 333/2014 of the European Parliament and of the Council of 11 March 2014 amending Regulation (EC) No 443/2009 to define the modalities for reaching the 2020 target to reduce $\mathrm{CO} 2$ emissions from new passenger cars).

It is also important to identify the data outliers to understand their impact on the final CI results, since these points could become unintentional benchmarks. In a dataset, the outliers are the values that are far from most of the other points. To visualize the data and spot these unusual data points, a boxplot can be used to show the empiric distribution of the data through the inter quartile range $(I Q R)$, that extends from the first quartile $(Q 1)$ to the third quartile $(Q 3)$. The $I Q R$ is a variability measure, i.e., a small $I Q R$ signify a low data variability. The "whiskers" extend from the $Q 1$ to $Q 1-1.5 \times I Q R$ and from the $Q 3$ to $Q 3+1.5 \times I Q R$. The outliers are the observations marked by circles that are outside the "whiskers" [44]. Figures 5.1 and 5.2 show the boxplot of each sub-indicator dataset with the outliers, when they are presented, identified in blue.

Except from the road deaths and the new car emissions sub-indicators, all the others subindicators had the presence of at least four outliers, which, most of the times, were values from the same country. In the share of public transport, Hungary was ahead of all of the other countries in all four years, followed by Czechia and Slovakia in 2018. Concerning the share of renewable energy, Sweden (2015, 2016, 2017 and 2018) and Finland (2015, 2017 and 2018) were the outliers in the dataset with much higher use of renewable fuels in transport. In the boxplot of the freight transport data, only Latvia was marked as an outlier. In all the years under analysis the country presented a higher share of freight transport made by rail and inland waterways.

Typically, the "whiskers" are much longer than the box, as it was observed in the freight transport, road deaths and new car emissions. Short "whiskers" can be observed in the GHG emissions boxplot, where most of the data was concentrated around the same value, and the size of the box was small. Luxembourg was the only outlier with much higher emissions in all four years. The boxplot for the energy dependency dataset was also characterized by a small box and short "whiskers". The sub-indicator was also the one with the most outliers. Estonia in 2017 and Sweden in 2015 were outliers with a higher value of energy dependency than the majority of the other units. Croatia (2015, 2016 and 2017), Romania, United Kingdom and Denmark (all in 

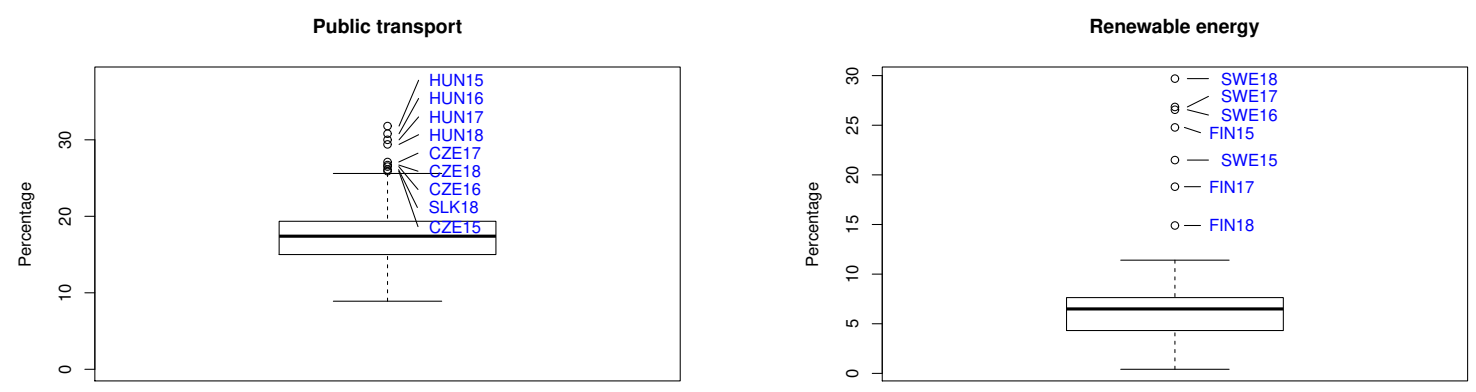

(a) Boxplot of public transport data.

(b) Boxplot of renewable energy data.

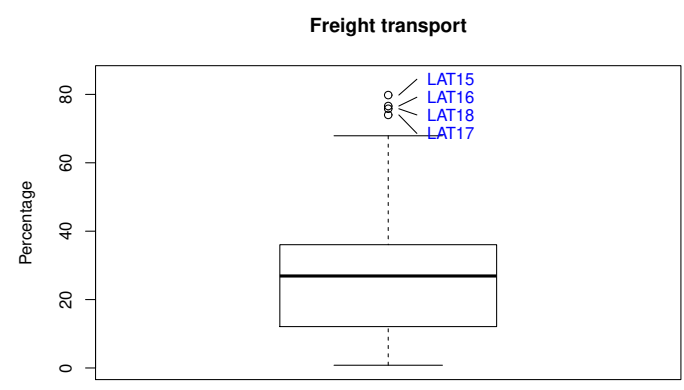

(c) Boxplot of freight transport data.

Figure 5.1: Boxplot of the forward sub-indicators data.

2015, 2016, 2017 and 2018) were outliers with lower values of energy dependency.

\subsection{Performance assessment of the EU countries}

The transport environmental performance for each country in a given year was computed by aggregating the seven chosen sub-indicators into a CI using the DEA models (2.4) and (2.7). These two models are used to facilitate the comparison. The first model is the conventional BoD model, using the Constant linear transformation technique to transform the data of the anti-isotonic sub-indicators. The formulation for the model is given by (5.1) and referred from now on as $\mathrm{BoD}(\mathrm{K})$. 


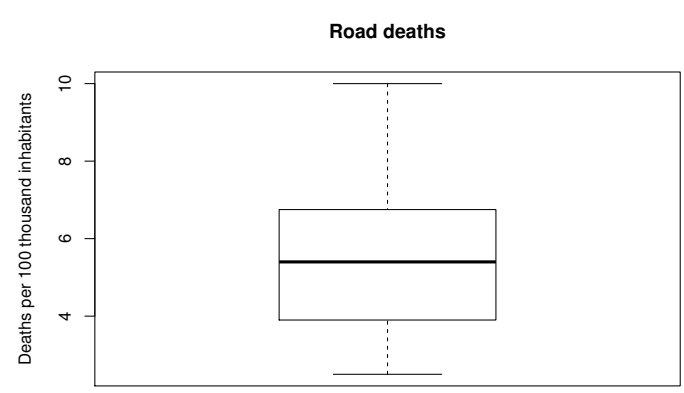

(a) Boxplot of road deaths data.

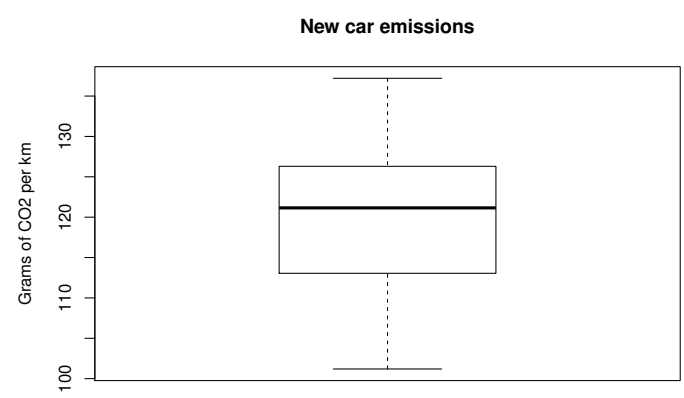

(c) Boxplot of new car emissions data.

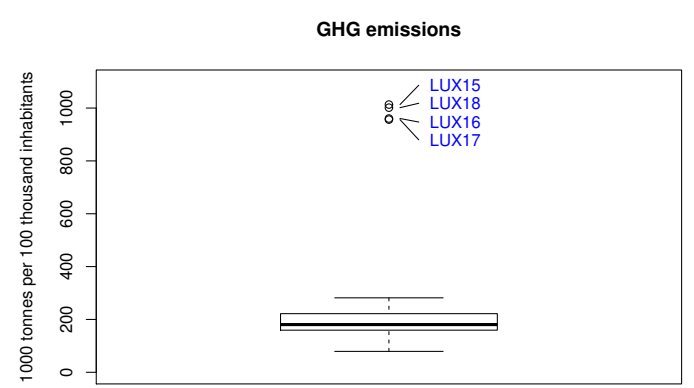

(b) Boxplot of GHG emissions data.

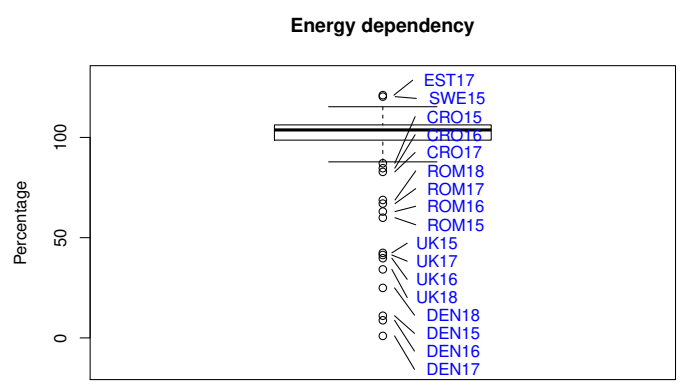

(d) Boxplot of energy dependency data.

Figure 5.2: Boxplot of the reverse sub-indicators data.

$$
\begin{array}{ll}
\mathbf{C I}_{j_{0}}= & \max \sum_{i=1}^{m} w_{i} y_{i j_{0}} \\
\text { s.t. } & \sum_{i=1}^{m} w_{i} y_{i j} \leq 1 \quad \forall j=1, \ldots, s \\
& \frac{w_{i} y_{i j_{0}}}{\sum_{i=1}^{m} w_{i} y_{i j_{0}}} \geq 0.05 \quad \forall i=1, \ldots, m \\
& w_{i} \geq 0 \quad \forall i=1, \ldots, m
\end{array} .
$$

The second model used is the variant BoD model proposed by Färe, et al. in [14] that does not require any transformation on the reverse sub-indicators. The model is given by (5.2), and referred as FKHM. 


$$
\begin{aligned}
\mathrm{CI}_{j_{0}}= & \max \sum_{i=1}^{m} w_{i} y_{i j_{0}}-\sum_{i=m+1}^{M} w_{i} y_{i j_{0}} \\
\text { s.t. } \quad & \sum_{i=1}^{m} w_{i} y_{i j}-\sum_{i=m+1}^{M} w_{i} y_{i j} \leq 1 \quad \forall j=1, \ldots, s \\
& \frac{w_{i} y_{i j_{o}}}{\sum_{i=1}^{m} w_{i} y_{i j_{0}}+\sum_{i=m+1}^{M} w_{i} y_{i j_{0}}} \geq 0.05 \quad \forall i=1, \ldots, M \\
& w_{i} \geq 0 \quad \forall i=1, \ldots, M
\end{aligned}
$$

Both models incorporate the sub-indicator share restriction (2.6). It was defined that each sub-indicator share should have a contribution of at least $5 \%, \alpha=0.05$. This value was chosen as it was sufficient to prevent the attribution of zero weights at any sub-indicator, thus, guaranteeing the contribution of all sub-indicators in the final CI and increasing the countries' discrimination in the performance assessment. The usual value for $\alpha=0.10$ found on literature was not used, as this value ends up penalizing countries under-performing in a single sub-indicator, and, in these conditions, very few countries in the data set would be efficient.

The CI of the transport environmental performance was calculated using the data from the time span of four years, from 2015 to 2018 and is assessed by comparison to the best practices observed during this complete time period. The results are presented in Table A.1 in the Appendix. The CI average for each model is summarized in Figure 5.3.

When using the $\mathrm{BoD}(\mathrm{K})$ model 10 units were considered efficient: Denmark (in 2015 and 2017), Latvia (in 2018), Hungary (in 2015, 2016 and 2017), Netherlands (in 2015 and 2018) and Sweden (in 2017 and 2018). The average of the CI scores in the four years when using this model was of 0.735 . The CI varied slightly during these four years, settling in 2018 at 0.773 , $7.80 \%$ above 2015 levels. The average standard deviation in the four years under analysis was of 0.256. The standard deviation decreased in 2018 and was $7.9 \%$ bellow 2015 levels.

With the FKHM model, 12 units were efficient: Denmark (in 2017), Latvia (in 2015 and 2018), Hungary (in 2015, 2016 and 2017), Netherlands (in 2015, 2017 and 2018), Romania (in 2015) and Sweden (in 2017 and 2018). The average of the CI results in the four years analysed was around 0.589 . Through the FKHM model, the average of the environmental performance 


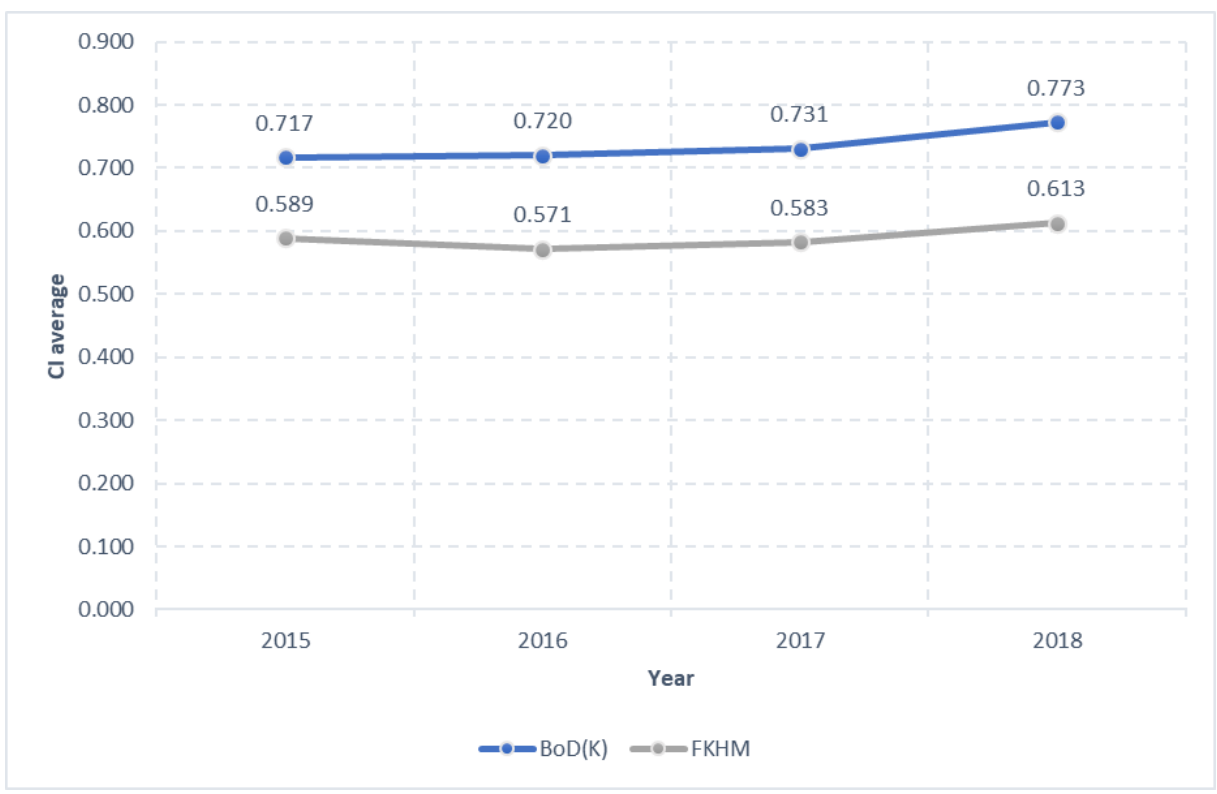

Figure 5.3: Evolution of the average of the EU countries' CI score from 2015 to 2018.

had only slight variations through the years. Thus, this average decreased by almost 3\% in 2016 when compared to 2015, but began to increase in 2017. By 2018 the CI average was $4.09 \%$ above 2015 levels. The average of the standard deviation for the four years analysed was 0.280. Between 2015 and 2018 it decreased by $9.6 \%$, showing that the countries are heading towards a larger homogeneity regarding the transport sustainability.

The average of the FKHM model in the time frame analysed is almost $20 \%$ lower than the average of the $\operatorname{BoD}(\mathrm{K})$ model. The most noticeable differences between the $\mathrm{BoD}(\mathrm{K})$ and the FKHM results were on the CI results for Portugal and the United Kingdom, in which the FKHM results were more than $50 \%$ lower than the $\mathrm{BoD}(\mathrm{K})$ results. There were also 11 other countries in which the CI scores were more than $30 \%$ lower in the FKHM model when compared to the $\operatorname{BoD}(\mathrm{K})$ model: Belgium, Germany, Estonia, Ireland, Greece, Spain, France, Croatia, Italy, Cyprus and Malta. All these countries had better performances on reverse sub-indicators and not so great values on the forward sub-indicators and, as previously mentioned, the FKHM model attributes higher CI scores to better performances on forward sub-indicators than on the reverse sub-indicators.

Hereinafter, the analysis will be made only using the results from the FKHM model, because this method has the advantage of removing the necessity of using transformation techniques for 
the anti-isotonic sub-indicators.

Table 5.2 shows the CI results obtained through the FKHM model ranked by their average CI, from the highest to the lowest score.

Table 5.2: CI results using the FKHM model with countries ranked by their average CI results

\begin{tabular}{|c||c|c|c|c||c|}
\hline \hline Country & $\mathbf{2 0 1 5}$ & $\mathbf{2 0 1 6}$ & $\mathbf{2 0 1 7}$ & $\mathbf{2 0 1 8}$ & Mean \\
\hline \hline Hungary & 1.000 & 1.000 & 1.000 & 0.919 & $\mathbf{0 . 9 8 0}$ \\
\hline Netherlands & 1.000 & 0.910 & 1.000 & 1.000 & $\mathbf{0 . 9 7 8}$ \\
\hline Romania & 1.000 & 0.975 & 0.945 & 0.922 & $\mathbf{0 . 9 6 0}$ \\
\hline Sweden & 0.877 & 0.937 & 1.000 & 1.000 & $\mathbf{0 . 9 5 3}$ \\
\hline Denmark & 0.949 & 0.922 & 1.000 & 0.777 & $\mathbf{0 . 9 1 2}$ \\
\hline Latvia & 1.000 & 0.848 & 0.792 & 1.000 & $\mathbf{0 . 9 1 0}$ \\
\hline Slovakia & 0.884 & 0.927 & 0.893 & 0.912 & $\mathbf{0 . 9 0 4}$ \\
\hline Austria & 0.791 & 0.788 & 0.772 & 0.804 & $\mathbf{0 . 7 8 9}$ \\
\hline Lithuania & 0.787 & 0.762 & 0.782 & 0.823 & $\mathbf{0 . 7 8 9}$ \\
\hline Czechia & 0.759 & 0.787 & 0.811 & 0.789 & $\mathbf{0 . 7 8 6}$ \\
\hline Finland & 0.791 & 0.610 & 0.730 & 0.685 & $\mathbf{0 . 7 0 4}$ \\
\hline Bulgaria & 0.694 & 0.685 & 0.654 & 0.651 & $\mathbf{0 . 6 7 1}$ \\
\hline Poland & 0.632 & 0.600 & 0.594 & 0.617 & $\mathbf{0 . 6 1 1}$ \\
\hline Belgium & 0.547 & 0.564 & 0.582 & 0.597 & $\mathbf{0 . 5 7 3}$ \\
\hline Germany & 0.524 & 0.543 & 0.537 & 0.547 & $\mathbf{0 . 5 3 8}$ \\
\hline Italy & 0.533 & 0.539 & 0.502 & 0.536 & $\mathbf{0 . 5 2 8}$ \\
\hline France & 0.532 & 0.520 & 0.532 & 0.522 & $\mathbf{0 . 5 2 7}$ \\
\hline Luxembourg & 0.485 & 0.465 & 0.484 & 0.486 & $\mathbf{0 . 4 8 0}$ \\
\hline Slovenia & 0.469 & 0.396 & 0.492 & 0.540 & $\mathbf{0 . 4 7 4}$ \\
\hline UK & 0.415 & 0.403 & 0.409 & 0.472 & $\mathbf{0 . 4 2 5}$ \\
\hline Croatia & 0.461 & 0.326 & 0.319 & 0.481 & $\mathbf{0 . 3 9 7}$ \\
\hline Portugal & 0.367 & 0.384 & 0.384 & 0.402 & $\mathbf{0 . 3 8 4}$ \\
\hline Spain & 0.292 & 0.440 & 0.377 & 0.394 & $\mathbf{0 . 3 7 6}$ \\
\hline Estonia & 0.155 & 0.157 & 0.153 & 0.708 & $\mathbf{0 . 2 9 3}$ \\
\hline Greece & 0.189 & 0.162 & 0.216 & 0.242 & $\mathbf{0 . 2 0 2}$ \\
\hline Ireland & 0.140 & 0.124 & 0.131 & 0.117 & $\mathbf{0 . 1 2 8}$ \\
\hline Malta & 0.113 & 0.112 & 0.116 & 0.118 & $\mathbf{0 . 1 1 5}$ \\
\hline Cyprus & 0.108 & 0.108 & 0.108 & 0.108 & $\mathbf{0 . 1 0 8}$ \\
\hline \hline & & & & & \\
\hline
\end{tabular}

From 2015 to 2018, most of the countries improved their transport environmental performance. The highest improvement were observed in Estonia, Spain and Greece, which increased their CI scores in 2018 by $358.1 \%, 34.9 \%$ and $27.6 \%$ above 2015 levels, respectively. This high increase in the CI score of Estonia is due to a 16\% reduction in the country's energy dependency 
and an increase of renewable energies in transport of more than six times 2015 values. The highest decreases during this time frame were observed for Denmark (18.1\%), Ireland (16.1\%) and Latvia (13.3\%).

Ireland, Malta and Cyprus were the most inefficient countries in this analysis. Besides Ireland that had decreased its CI score, Malta and Cyprus had improvements of $4.5 \%$ and $0.5 \%$, respectively, in 2018 when compared to 2015 scores.

To further facilitate the visualization of the countries performance, Figure 5.4 shows the CI results from 2018 in the European map. The efficient countries were presented in dark green and the most inefficient countries in red.

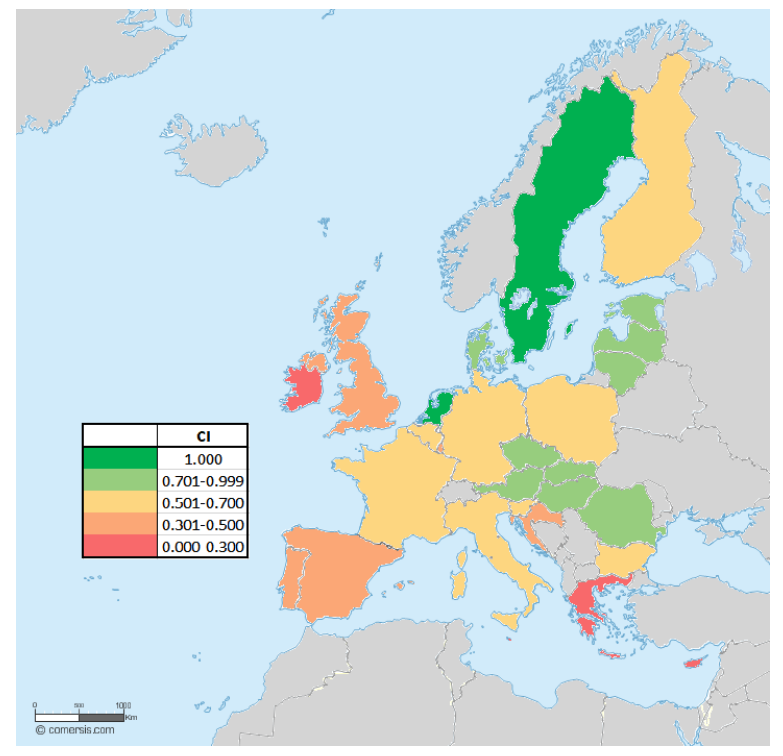

Figure 5.4: Map of the countries CI results from 2018.

\subsubsection{Benchmark analysis}

Using the dual formulation of the FKHM model (5.2), given by (2.8) taking into account the sub-indicators share limitation, it is possible to perform a benchmark analysis for each country. The degree of intensity of each benchmark $j$ in each country's evaluation is given by the dual variables $\lambda_{j}$, which are retrieved from the dual of the FKHM model (5.2). Through this analysis it is possible to obtain the $\lambda_{j}$ that identifies to which benchmark units each country is compared to obtain its CI value. The number of times each benchmark was used by the inefficient units is 
summarized in Figure 5.5. Table A.2 shows the benchmarks used by each unit to obtain their relative performance.

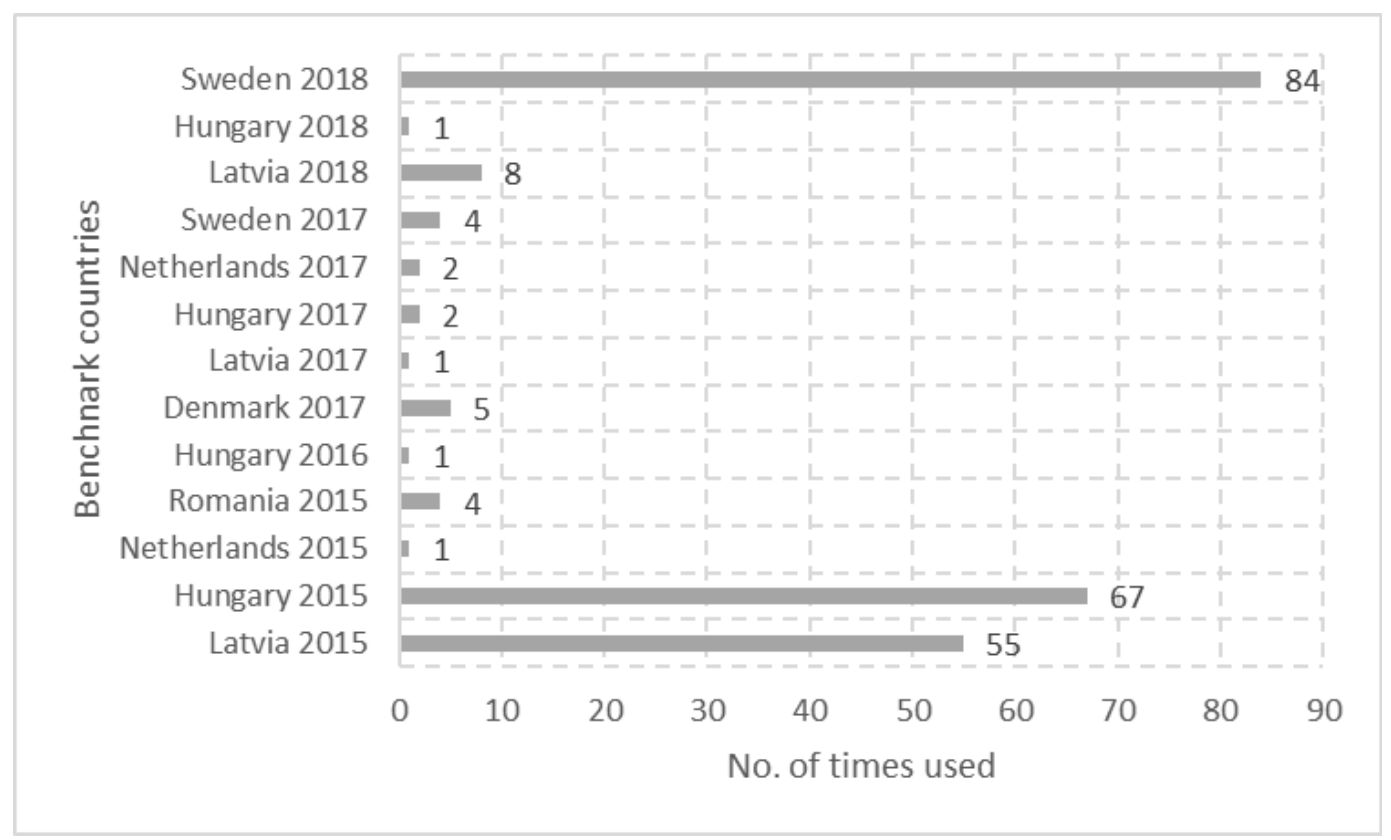

Figure 5.5: Frequency of use of the benchmarks.

Sweden in 2018 was the benchmark unit most used by the inefficient countries to obtain their performance, followed by Hungary and Latvia in 2015. The other benchmarks were used in a much lower frequency.

With the $\lambda_{j}$ values it is also possible to calculate the target sub-indicators values for each inefficient country to become efficient. In order to exemplify the calculation of the target sub-indicator values, the $\lambda_{j}$ values for Portugal were used. In 2018, this country has two benchmark units to calculate its performance: Hungary in 2015 and Sweden in 2018. The $\lambda_{j}$ value for Hungary was $\lambda_{H U N 15}=0.1947$ and for Sweden was $\lambda_{S W E 18}=0.2074$. Based on these values, the contribution of Hungary (in 2015) and Sweden (in 2018) are respectively, $48.43 \%$ and $51.57 \%$, which are used to obtain the sub-indicator values for Portugal that would make it efficient. Let $y_{P O R 18_{a}}$ be the desirable value for Portugal in 2018 for the sub-indicator $a$, and let $y_{H U N 15_{a}}$ and $y_{S W E 18_{a}}$ be the sub-indicator $a$ values for Hungary in 2015 and Sweden in 2018, respectively. To obtain the desirable sub-indicator $a$ value for Portugal in 2018 the formulation used is: $y_{P O R 18_{a}}=48.43 \% \times y_{H U N 15_{a}}+51.57 \% \times y_{S W E 18_{a}}$. Table 5.3 shows the 
original sub-indicator values for Portugal, the target values obtained using the dual model and the improvement needed in percentage.

Table 5.3: Comparison between the sub-indicator values from Portugal and the its target benchmark values.

\begin{tabular}{|c||c|c||c|}
\hline Sub-indicator & Original & Target & Improvement \\
\hline \hline Public transport & 11.600 & 24.115 & $107.892 \%$ \\
\hline Renewable energy & 9.037 & 18.787 & $107.892 \%$ \\
\hline Freight transport & 14.200 & 32.940 & $131.973 \%$ \\
\hline Road deaths & 6.800 & 4.798 & $-29.441 \%$ \\
\hline GHG emissions & 167.599 & 144.000 & $-14.081 \%$ \\
\hline New car emissions & 106.100 & 125.784 & $0 \%$ \\
\hline Energy dependency & 109.885 & 99.585 & $-9.374 \%$ \\
\hline \hline
\end{tabular}

Analysing the results presented in the table it is possible to conclude that Portugal needs to improve mostly on the forward sub-indicators: the country needs to increase drastically its share of public transport, the share of freight transport made by rail and inland waterways and the share of renewable energy in transport. There is also area for improvement in reducing the number of road deaths, GHG emissions and energy dependency. Portugal already had good values related to the new car emissions sub-indicator and the target value calculated for this reverse sub-indicators was higher than the original. Since the target is obtained by a linear combination of both benchmarks, a higher value is possible. By following the benchmarks performance, Portugal's tendency would be to increase its new car emissions, being necessary to implement European policies against this tendency.

\subsubsection{Radar analysis}

This study also uses the efficient countries, which obtained a CI score of one, as benchmarks and compares their performance on the forward and reverse sub-indicators with that on the inefficient countries. The mean for each sub-indicator is calculated for both groups (benchmarks and inefficient countries). Figure 5.6 shows a comparison for each sub-indicator between the benchmark and the inefficient countries. The reverse sub-indicators were highlighted in red and the forward ones in green. 


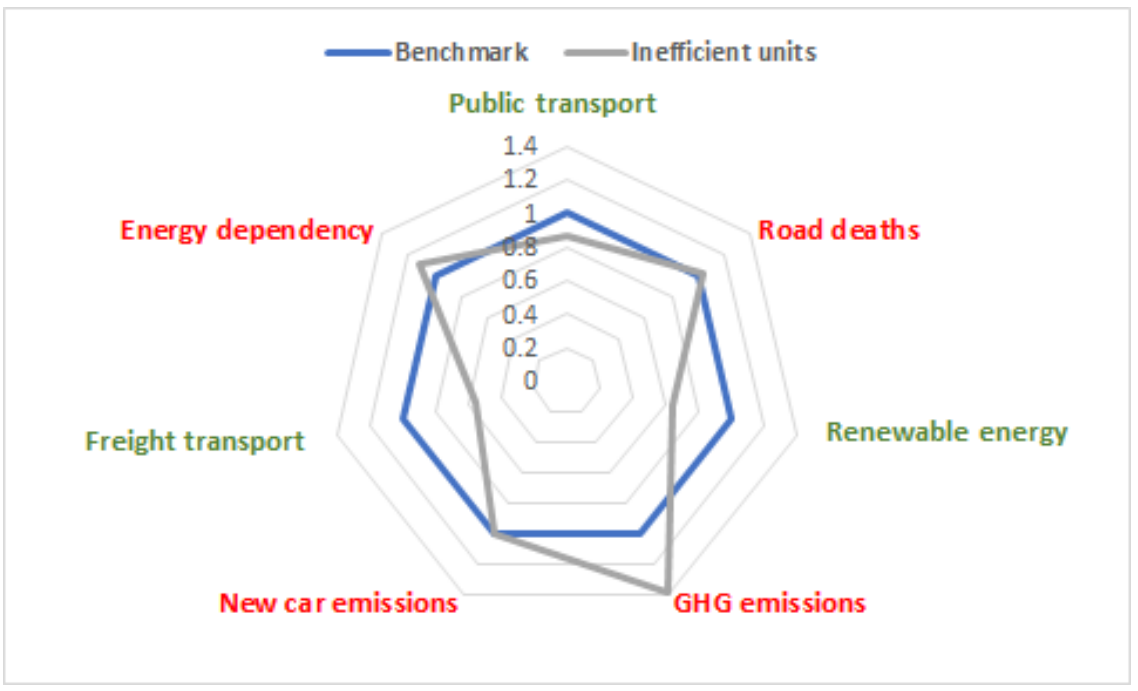

Figure 5.6: Comparison between benchmarks and inefficient countries.

Analysing Figure 5.6, it is possible to notice the areas where the inefficient countries need improvement by setting out policies and/or redefine output standards, for instance. Except for the number of road deaths and new car emissions sub-indicators, in which both groups had a very similar performance, the inefficient countries were always outperformed by the benchmarks. Analysing the forward sub-indicators (green colored) the inefficient countries has about $86 \%$ of the share of public transport presented by the benchmarks and $64 \%$ of the renewable energy share presented by the benchmark group. In the freight transport sub-indicator, the inefficient countries have less than $55 \%$ of the value presented for the benchmarks. Considering the reverse sub-indicators (red colored), the inefficient countries had a value of GHG emissions almost $40 \%$ higher than the benchmarks. The average of energy dependency sub-indicator of the inefficient countries was $10 \%$ higher than the benchmarks.

Most of the work to improve transport sustainability should be done in reducing the $G H G$ emissions from fossil fuel, improving the infrastructure and promote policies to increase the share of freight transport that uses rail and inland waterways and also increasing the share of energy from renewable sources in transport. There is also still margin to increase the use of public transport of the inefficient countries by improving its accessibility and quality to allow a larger share of passenger to benefit from it and to reduce the oil and petroleum dependency through changes in the transport energy consumption. 


\subsection{CI results versus environmental taxes revenues}

The analysis of how environmental taxes revenues impact on CI results was performed as follows. A comparison between the countries' CI and the transport environmental taxes revenue (normalized using the countries' population) was made for each year. Figure 5.7 shows the CI average using the FKHM model and the average transport environmental taxes, in million euro per hundred thousand inhabitants, for each year.

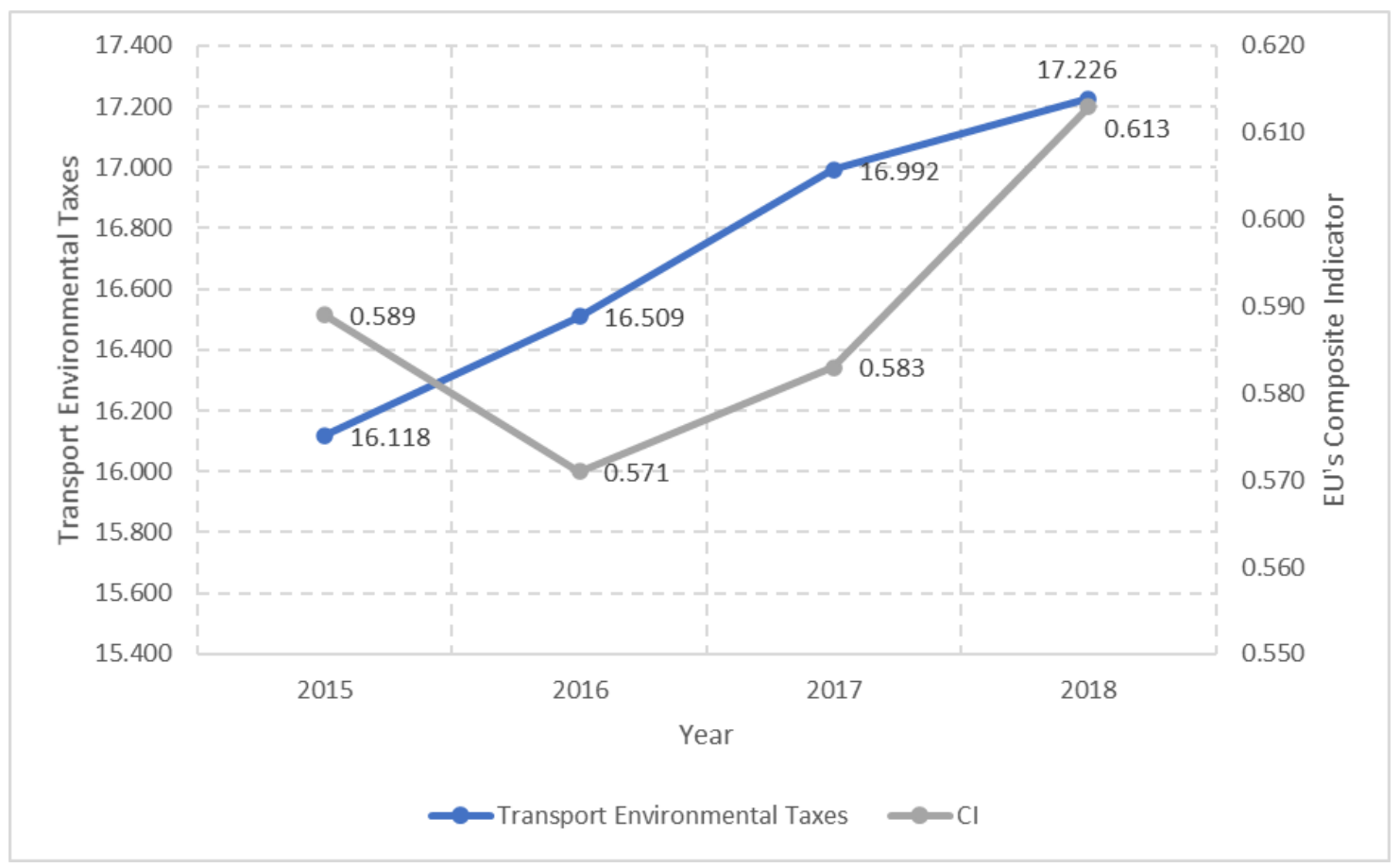

Figure 5.7: Variation of the CI average and the transport environmental taxes average.

The average of the transport environmental taxes from all EU-28 countries, in contrast with the CI results, have increased in the four years analysed and by 2018 was $6.87 \%$ above 2017. Table 5.4 shows the countries' CI results and the transport environmental taxes revenue in 2018, ranked by their taxes revenue, from highest to lowest value. Countries with a CI score above 0.900 were highlighted in green and the ones with a CI bellow 0.300 were highlighted in red. Analysing the individual values from each country it is seen that some of the countries with higher CI scores had a lower average environmental taxes revenue, while most of the countries with a lower CI results had a higher transport environmental taxes revenue. This outcome may 
indicate that the countries that under-performed in the transport sub-indicators may be taking action to improve their performance by changing their policies. However, there is not a clear correlation between these two results.

Table 5.4: 2018 CI results and transport environmental taxes.

\begin{tabular}{|c||c|c|}
\hline \hline Country & Taxes & CI \\
\hline \hline Denmark & 78.079 & 0.777 \\
\hline Netherlands & 46.924 & 1.000 \\
\hline Finland & 40.231 & 0.685 \\
\hline Ireland & 39.258 & 0.117 \\
\hline Austria & 37.346 & 0.804 \\
\hline Malta & 27.482 & 0.118 \\
\hline Belgium & 26.458 & 0.597 \\
\hline Sweden & 20.327 & 1.000 \\
\hline UK & 19.718 & 0.472 \\
\hline Italy & 17.944 & 0.536 \\
\hline Cyprus & 14.003 & 0.108 \\
\hline Portugal & 13.944 & 0.402 \\
\hline Greece & 13.546 & 0.242 \\
\hline Germany & 12.379 & 0.547 \\
\hline Luxembourg & 11.284 & 0.486 \\
\hline Croatia & 10.127 & 0.481 \\
\hline France & 10.108 & 0.522 \\
\hline Slovenia & 9.607 & 0.540 \\
\hline Spain & 6.128 & 0.394 \\
\hline Latvia & 5.986 & 1.000 \\
\hline Hungary & 5.71 & 0.919 \\
\hline Slovakia & 4.273 & 0.912 \\
\hline Poland & 3.02 & 0.617 \\
\hline Czechia & 2.473 & 0.789 \\
\hline Bulgaria & 2.471 & 0.651 \\
\hline Lithuania & 1.371 & 0.823 \\
\hline Romania & 1.117 & 0.922 \\
\hline Estonia & 1.003 & 0.708 \\
\hline \hline
\end{tabular}

Figure 5.8 shows a comparison analysis of the countries' CI results compared to their transport environmental taxes revenues from 2018. Besides, the correlation and p-value between the two datasets was $-0.0303(0.8785)$. These results corroborate that there is no clear correlation between $\mathrm{CI}$ results and the transport environmental taxes revenue. 


\subsection{CI results versus environmental taxes revenues}

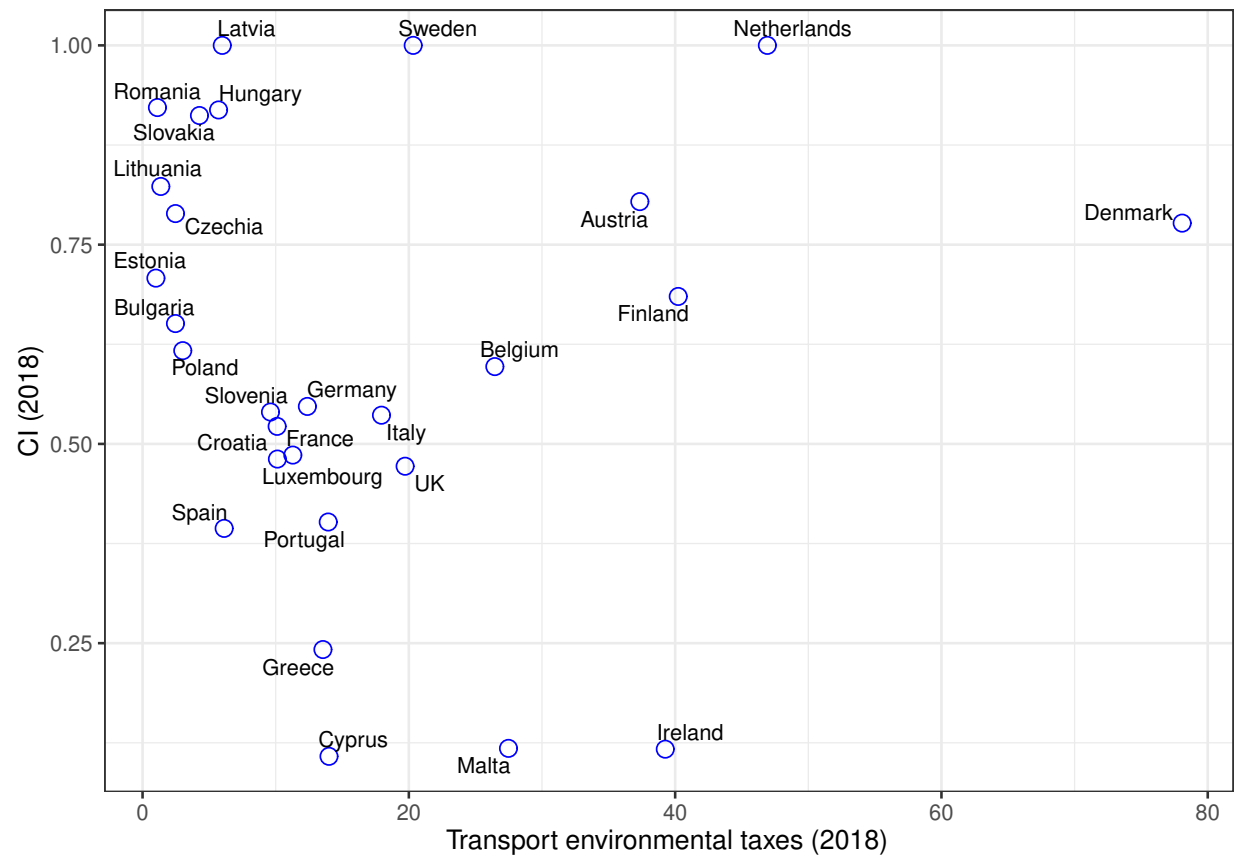

Figure 5.8: Comparison between the CI results and the 2018 transport environmental taxes. 



\section{Chapter 6}

\section{Conclusions}

This study aimed at evaluating the environmental performance of the transport sector in the 28 countries of the European Union, from 2015 and 2018, towards the policy agenda established in strategic documents. Based on literature review, the targets set on transport strategic documents, the data available for all the EU countries and considering their empirical sensitivity analysis, seven transport sub-indicators were selected for the assessment. Three sub-indicators were forward, measuring a positive aspect: the share of buses and trains in total passengers' transport, the share of energy from renewable sources in transport and the share of rail and inland waterways in total freight transport. And four sub-indicators were anti-isotonic or reverse, measuring the negative aspect: people dead on road accidents, the GHG emissions by fuel combustion in transport, the average $\mathrm{CO}_{2}$ emissions per kilometer from new passenger cars and the energy dependency on oil and petroleum imports.

Examples including a small number of units were used to better understand the BoD model, the need to include the sub-indicators share restriction and the evaluation of the best option to deal with the reverse sub-indicators. In the latter, four transformations techniques for the anti-isotonic sub-indicators in the BoD model were compared to the variant of the BoD model proposed by Färe et al. [14], the FKHM model, which does not required any transformation. In this analysis, it was concluded that the FKHM model, when compared to the BoD model using transformed reverse sub-indicator through any technique, rewards more the units that have a good performance in the forward sub-indicator than in the reverse sub-indicator and penalize more those that had higher values in the reverse sub-indicator. Considering these arguments and the advantage of the FKHM model which does not required any transformation to adequate the reverse sub-indicators, this model was chosen to assess the environmental performance of the transport sector in the EU countries. It should be point out that the application of FKHM 
model to the assessment of the transport sustainability is somehow innovative, because it had not been performed previously, as far the knowledge of the author. Additionally, the FKHM model's results were also compared to the conventional $\mathrm{BoD}$ model's results, using the Constant technique to transform the reverse sub-indicators, $\mathrm{BoD}(\mathrm{K})$, enabling to conclude that the FKHM model's results represented better the performance of the countries than the $\mathrm{BoD}(\mathrm{K})$ results in the analysed scenario.

Based on the results achieved with the FKHM model, it is possible to conclude that, in general, the transport environmental performance of the EU countries has improved in the last two years and by 2018 was $4.09 \%$ above 2015 levels. This result points out that EU countries are making efforts in the right direction and the countries are strengthening their ability towards sustainability.

The performance assessment identified 12 efficient units: Denmark (in 2017), Latvia (in 2015 and 2018), Hungary (in 2015, 2016 and 2017), Netherlands (in 2015, 2017 and 2018), Romania (in 2015) and Sweden (in 2017 and 2018). By using these units as benchmarks and comparing their performance in each sub-indicator with the remaining units (the inefficient ones), it was possible to identify the areas that need improvement. Most of the work to improve transport sustainability should be done by reducing drastically the greenhouse gas emissions from fossil fuel combustion, increasing the share of freight transport that uses rail and inland waterways and also the share of transport energy from renewable sources.

Future work should explore other models for treating anti-isotonic sub-indicators in order to allow results comparison among those different models. Furthermore, some other sub-indicators can be taken into account, to calculate the composite indicator for each country. 


\section{References}

[1] A Dobranskyte-Niskota, A Perujo, and M Pregl, "Indicators to assess sustainability of transport activities", European Comission, Joint Research Centre, 2007.

[2] V. Bulc and H. Hololei, Transport in the European Union - current trends and issues, ser. Mobility and Transport. 2019.

[3] L. P. O. of the European Union, EU Transport in figures. Statistical pocketbook 2019, ser. Mobility and Transport. Imprimerie Bietlot Frères in Belgium, 2019, ISBN: 9789276038436.

[4] European Comission. (2018). EU mobility package: Europe on the move briefing note, [Online]. Available: http://nws.eurocities.eu/MediaShell/media/EuropeonthemoveBriefingnote.pdf.

[5] _ (2011). Proposal for a regulation of the european parliament and of the council setting CO2 emission performance standards for new heavy duty vehicles, [Online]. Available: https://eur-lex.europa.eu/legalcontent/EN/TXT/?uri=SWD:2018:185:FIN.

[6] E. E. Agency, Progress of EU transport sector towards its environment and climate objectives, ser. Transport and Environment Reporting Mechanism. 2018, ISBN: 978929480206.

[7] European Comission, "White paper on transport: Roadmap to a single european transport area: Towards a competitive and resource-efficient transport system", 2011.

[8] (). About the sustainable development goals, [Online]. Available: https://www.un.org/sustainabledevelopment/ sustainable-development-goals/.

[9] H. Gudmundsson and M. B. Regmi, "Developing the sustainable urban transport index", Transport and Sustainable Development Goals, p. 35, 2017.

[10] D. Bongardt, D. Schmid, C. Huizenga, and T. Litman, "Sustainable transport evaluation: Developing practical tools for evaluation in the context of the csd process", Partnership on Sustainable Low Carbon Transport, Eschborn, Germany, 2011.

[11] N. Kunicina, P Waeger, E Calderon, R Arce, R Joumard, J. Nicolas, A Tennøy, F Ramjerdi, M Ruzicka, $\mathrm{G}$ Arapis, et al., Indicators of environmental sustainability in transport. An interdisciplinary approach to methods. 2010.

[12] M. Reisi, L. Aye, A. Rajabifard, and T. Ngo, "Transport sustainability index: Melbourne case study", Ecological Indicators, vol. 43, pp. 288-296, 2014. 
[13] R. Danielis, L. Rotaris, and A. Monte, "Composite indicators of sustainable urban mobility: Estimating the rankings frequency distribution combining multiple methodologies", International Journal of Sustainable Transportation, vol. 12, no. 5, pp. 380-395, 2018.

[14] R. Färe, G. Karagiannis, M. Hasannasab, and D. Margaritis, "A benefit-of-the-doubt model with reverse indicators", European Journal of Operational Research, vol. 278, no. 2, pp. 394-400, 2019.

[15] G. Mitchell, A May, and A McDonald, "PICABUE: A methodological framework for the development of indicators of sustainable development", The International Journal of Sustainable Development \& World Ecology, vol. 2, no. 2, pp. 104-123, 1995.

[16] A. Hoffmann and E. Giovannini, Handbook on constructing composite indicator: methodology and users guide. OECD, 2008, ISBN: 9789264043459.

[17] P. Zhou, B. Ang, and K. Poh, "A mathematical programming approach to constructing composite indicators", Ecological economics, vol. 62, no. 2, pp. 291-297, 2007.

[18] L. Cherchye, W. Moesen, N. Rogge, and T. Van Puyenbroeck, "An introduction to 'benefit of the doubt' composite indicators", Social indicators research, vol. 82, no. 1, pp. 111-145, 2007.

[19] A. Charnes, W. W. Cooper, and E. Rhodes, "Measuring the efficiency of decision making units", European journal of operational research, vol. 2, no. 6, pp. 429-444, 1978.

[20] W. W. Cooper, L. M. Seiford, and K. Tone, "Data envelopment analysis: A comprehensive text with models, applications, references and dea-solver software", vol. 52, no. 12, 2002.

[21] H. O. Fried, S. S. Schmidt, and C. K. Lovell, The measurement of productive efficiency: techniques and applications. Oxford university press, 1993.

[22] E. Reig-Martínez, J. A. Gómez-Limón, and A. J. Picazo-Tadeo, "Ranking farms with a composite indicator of sustainability", Agricultural economics, vol. 42, no. 5, pp. 561-575, 2011.

[23] R. G. Dyson, R. Allen, A. S. Camanho, V. V. Podinovski, C. S. Sarrico, and E. A. Shale, "Pitfalls and protocols in dea", European Journal of operational research, vol. 132, no. 2, pp. 245-259, 2001.

[24] W. Melyn, W. Moesen, and K. U. te Leuven (1970-). Centrum voor Economische Studiën, Towards a Synthetic Indicator of Macroeconomic Performance: Unequal Weighting when Limited Information is Available, ser. Public economics research papers. Katholieke Universiteit Leuven, 1991. [Online]. Available: https://books.google.pt/books?id=5hLXSAAACAAJ.

[25] W Chung, "Using dea model without input and with negative input to develop composite indicators", in 2017 IEEE International Conference on Industrial Engineering and Engineering Management (IEEM), IEEE, 2017, pp. 2010-2013. 
[26] L. Cherchye, W. Moesen, N. Rogge, T. Van Puyenbroeck, M. Saisana, A. Saltelli, R. Liska, and S. Tarantola, "Creating composite indicators with dea and robustness analysis: The case of the technology achievement index", Journal of the Operational Research Society, vol. 59, no. 2, pp. 239-251, 2008.

[27] Y.-H. Wong and J. Beasley, "Restricting weight flexibility in data envelopment analysis", Journal of the Operational Research Society, vol. 41, no. 9, pp. 829-835, 1990.

[28] C. K. Lovell, J. T. Pastor, and J. A. Turner, "Measuring macroeconomic performance in the oecd: A comparison of european and non-european countries", European journal of operational research, vol. 87, no. 3, pp. 507-518, 1995.

[29] H. Scheel, "Undesirable outputs in efficiency valuations", European journal of operational research, vol. 132, no. 2 , pp. 400-410, 2001.

[30] T. Litman, Well measured: Developing indicators for sustainable and livable transport planning. Victoria Transport Policy Institute, 2012.

[31] S. Imperatives, "Report of the world commission on environment and development: Our common future",

[32] J. Elkington, "Towards the sustainable corporation: Win-win-win business strategies for sustainable development", California management review, vol. 36, no. 2, pp. 90-100, 1994.

[33] A. Alonso, A. Monzón, and R. Cascajo, "Comparative analysis of passenger transport sustainability in european cities", Ecological Indicators, vol. 48, pp. 578-592, 2015.

[34] P. Zito and G. Salvo, "Toward an urban transport sustainability index: An european comparison", European Transport Research Review, vol. 3, no. 4, pp. 179-195, 2011.

[35] M. Lu, R. Xie, P. Chen, Y. Zou, and J. Tang, "Green transportation and logistics performance: An improved composite index", Sustainability, vol. 11, no. 10, p. 2976, 2019.

[36] R. Zope, N Vasudevan, S. S. Arkatkar, and G. Joshi, "Benchmarking: A tool for evaluation and monitoring sustainability of urban transport system in metropolitan cities of india", Sustainable cities and society, vol. 45, pp. 48-58, 2019.

[37] European Commission, "SHARES tool manual", Unit E.5: Energy, 2018. [Online]. Available: https : //ec.europa.eu/eurostat/documents/38154/4956088/SHARES+Manual+2018/37909ab2-8c1f-907b-2e97$3111 \mathrm{~d} 0691 \mathrm{~b} 9 \mathrm{f}$.

[38] _ - "Directive 2009/28/EC of the european parliament and of the council", Official Journal of the European Union, 2009. [Online]. Available: https://eur-lex.europa.eu/legal-content/EN/TXT/PDF/?uri= CELEX:32009L0028\&from=EN. 
[39] _ - "Directive 2018/2001 of the european parliament and of the council", Official Journal of the European Union, 2018. [Online]. Available: https://eur-lex.europa.eu/legal-content/EN/TXT/PDF/?uri=CELEX: 32018L2001\&from=EN.

[40] P. Morais and A. S. Camanho, "Evaluation of performance of european cities with the aim to promote quality of life improvements", Omega, vol. 39, no. 4, pp. 398-409, 2011.

[41] E. Commission, "Regulation (EU) 2019/631 of the european parliament and of the council", Official Journal of the European Union, 2019. [Online]. Available: https://eur-lex.europa.eu/legal-content/EN/TXT/PDF/ ?uri=CELEX:32018L2001\&from=EN.

[42] (). Eurostat database, [Online]. Available: https://ec.europa.eu/eurostat/data/database.

[43] J. P. M. De Sá, Applied statistics using SPSS, Statistica, MatLab and R. Springer Science \& Business Media, 2007.

[44] R. Dawson, “How significant is a boxplot outlier?", Journal of Statistics Education, vol. 19, no. 2, 2011. 


\section{Appendix A}

\section{Additional tables}

Table A.1: Transport environmental performance results.

\begin{tabular}{|c|c|c|c|c|c|c|c|c|}
\hline & \multicolumn{2}{|c|}{2015} & \multicolumn{2}{|c|}{2016} & \multicolumn{2}{|c|}{2017} & \multicolumn{2}{|c|}{2018} \\
\hline Country & $\operatorname{BoD}(K)$ & FKHM & $\operatorname{BoD}(K)$ & FKHM & $\operatorname{BoD}(\mathbf{K})$ & FKHM & $\operatorname{BoD}(K)$ & FKHM \\
\hline Belgium & 0.749 & 0.547 & 0.824 & 0.564 & 0.842 & 0.582 & 0.823 & 0.597 \\
\hline Bulgaria & 0.720 & 0.694 & 0.728 & 0.685 & 0.761 & 0.654 & 0.840 & 0.651 \\
\hline Czechia & 0.886 & 0.759 & 0.918 & 0.787 & 0.927 & 0.811 & 0.900 & 0.789 \\
\hline Denmark & 1.000 & 0.949 & 0.992 & 0.922 & 1.000 & 1.000 & 0.948 & 0.777 \\
\hline Germany & 0.804 & 0.524 & 0.818 & 0.543 & 0.817 & 0.537 & 0.831 & 0.547 \\
\hline Estonia & 0.231 & 0.155 & 0.235 & 0.157 & 0.226 & 0.153 & 0.803 & 0.708 \\
\hline Ireland & 0.230 & 0.140 & 0.209 & 0.124 & 0.210 & 0.131 & 0.188 & 0.117 \\
\hline Greece & 0.319 & 0.189 & 0.277 & 0.162 & 0.368 & 0.216 & 0.410 & 0.242 \\
\hline Spain & 0.419 & 0.292 & 0.692 & 0.440 & 0.662 & 0.377 & 0.661 & 0.394 \\
\hline France & 0.844 & 0.532 & 0.847 & 0.520 & 0.836 & 0.532 & 0.831 & 0.522 \\
\hline Croatia & 0.764 & 0.461 & 0.504 & 0.326 & 0.482 & 0.319 & 0.766 & 0.481 \\
\hline Italy & 0.842 & 0.533 & 0.864 & 0.539 & 0.839 & 0.502 & 0.847 & 0.536 \\
\hline Cyprus & 0.180 & 0.108 & 0.184 & 0.108 & 0.182 & 0.108 & 0.184 & 0.108 \\
\hline Latvia & 0.850 & 1.000 & 0.827 & 0.848 & 0.836 & 0.792 & 1.000 & 1.000 \\
\hline Lithuania & 0.881 & 0.787 & 0.885 & 0.762 & 0.905 & 0.782 & 0.922 & 0.823 \\
\hline Luxembourg & 0.533 & 0.485 & 0.593 & 0.465 & 0.631 & 0.484 & 0.551 & 0.486 \\
\hline Hungary & 1.000 & 1.000 & 1.000 & 1.000 & 1.000 & 1.000 & 0.970 & 0.919 \\
\hline Malta & 0.188 & 0.113 & 0.186 & 0.112 & 0.187 & 0.116 & 0.188 & 0.118 \\
\hline Netherlands & 1.000 & 1.000 & 0.966 & 0.910 & 0.993 & 1.000 & 1.000 & 1.000 \\
\hline Austria & 0.904 & 0.791 & 0.932 & 0.788 & 0.930 & 0.772 & 0.939 & 0.804 \\
\hline Poland & 0.814 & 0.632 & 0.760 & 0.600 & 0.768 & 0.594 & 0.802 & 0.617 \\
\hline Portugal & 0.831 & 0.367 & 0.857 & 0.384 & 0.844 & 0.384 & 0.806 & 0.402 \\
\hline Romania & 0.937 & 1.000 & 0.929 & 0.975 & 0.848 & 0.945 & 0.921 & 0.922 \\
\hline Slovenia & 0.631 & 0.469 & 0.536 & 0.396 & 0.667 & 0.492 & 0.785 & 0.540 \\
\hline Slovakia & 0.939 & 0.884 & 0.950 & 0.927 & 0.943 & 0.893 & 0.940 & 0.912 \\
\hline Finland & 0.876 & 0.791 & 0.853 & 0.610 & 0.910 & 0.730 & 0.892 & 0.685 \\
\hline Sweden & 0.850 & 0.877 & 0.940 & 0.937 & 1.000 & 1.000 & 1.000 & 1.000 \\
\hline UK & 0.844 & 0.415 & 0.852 & 0.403 & 0.844 & 0.409 & 0.883 & 0.472 \\
\hline "Mean & 0.717 & 0.589 & 0.720 & $\overline{0.571}$ & 0.731 & 0.583 & (0.773 & 0.613 \\
\hline Std. Dev & 0.261 & 0.291 & 0.264 & 0.282 & 0.261 & 0.287 & 0.240 & 0.263 \\
\hline
\end{tabular}


Table A.2: Benchmarks used by each country.

\begin{tabular}{|c|c|c|c|c|}
\hline Countries & 2015 & 2016 & 2017 & 2018 \\
\hline Belgium & LAT15 - HUN15 & $\begin{array}{l}\text { LAT15 - HUN15 - } \\
\text { SWE18 }\end{array}$ & $\begin{array}{l}\text { LAT15 - HUN15 - } \\
\text { SWE18 }\end{array}$ & $\begin{array}{l}\text { LAT15 - HUN15 - } \\
\text { SWE18 }\end{array}$ \\
\hline Bulgaria & $\begin{array}{l}\text { LAT15 - HUN15 - } \\
\text { SWE18 }\end{array}$ & $\begin{array}{l}\text { LAT15 - HUN15 - } \\
\text { SWE18 }\end{array}$ & $\begin{array}{l}\text { LAT15 - HUN15 - } \\
\text { SWE18 }\end{array}$ & $\begin{array}{l}\text { LAT15 - HUN15 - } \\
\text { SWE18 }\end{array}$ \\
\hline Czechia & HUN15 - SWE18 & HUN15 - SWE18 & HUN15 - SWE18 & HUN15 - SWE18 \\
\hline Denmark & HUN15 - DEN17 & HUN15 - DEN17 & DEN17 & $\begin{array}{l}\text { HUN15 - DEN17 - } \\
\text { SWE18 }\end{array}$ \\
\hline Germany & $\begin{array}{l}\text { LAT15 - HUN15 - } \\
\text { SWE18 }\end{array}$ & $\begin{array}{l}\text { LAT15 - HUN15 - } \\
\text { SWE18 }\end{array}$ & $\begin{array}{c}\text { LAT15 - HUN15 - } \\
\text { SWE18 }\end{array}$ & $\begin{array}{l}\text { LAT15 - HUN15 - } \\
\text { SWE18 }\end{array}$ \\
\hline Estonia & SWE18 & SWE18 & SWE18 & LAT15 - SWE18 \\
\hline Ireland & LAT15 - SWE18 & LAT15 - SWE18 & LAT15 & LAT15 \\
\hline Greece & LAT15 & LAT15 & LAT15 & LAT15 - SWE18 \\
\hline Spain & $\begin{array}{l}\text { SWE18 } \\
\end{array}$ & HUN15 - SWE18 & HUN15 - SWE18 & HUN15 - SWE18 \\
\hline France & HUN15 - SWE18 & HUN15 - SWE18 & HUN15 - SWE18 & HUN15 - SWE18 \\
\hline Croatia & $\begin{array}{l}\text { LAT15 - HUN15 - } \\
\text { SWE18 }\end{array}$ & SWE18 & SWE18 & $\begin{array}{l}\text { LAT15 - HUN15 - } \\
\text { SWE18 }\end{array}$ \\
\hline Italy & HUN15 - SWE18 & HUN15 - SWE18 & HUN15 - SWE18 & HUN15 - SWE18 \\
\hline Cyprus & LAT15 & LAT15 & LAT15 & LAT15 \\
\hline Latvia & LAT15 & SWE18 & SWE18 & LAT18 \\
\hline Lithuania & LAT15 - SWE18 & LAT15 - SWE18 & LAT15 - SWE18 & $\begin{array}{l}\text { LAT15 - LAT18 - } \\
\text { SWE18 }\end{array}$ \\
\hline Luxembourg & HUN15 - SWE18 & HUN15 - SWE18 & HUN15 - SWE18 & HUN15 - SWE18 \\
\hline Hungary & HUN15 & HUN16 & HUN17 & HUN15 - SWE18 \\
\hline Malta & LAT15 - SWE18 & LAT15 - SWE18 & LAT15 & LAT15 \\
\hline Netherlands & NET15 & SWE17 - LAT18 & NET17 & NET18 \\
\hline Austria & $\begin{array}{l}\text { LAT15 - HUN15 - } \\
\text { SWE18 }\end{array}$ & $\begin{array}{l}\text { LAT15 - HUN15 - } \\
\text { SWE18 }\end{array}$ & $\begin{array}{l}\text { LAT15 - HUN15 - } \\
\text { SWE18 }\end{array}$ & $\begin{array}{l}\text { LAT15 - HUN15 - } \\
\text { LAT18 - SWE18 }\end{array}$ \\
\hline Poland & $\begin{array}{l}\text { LAT15 - HUN15 - } \\
\text { SWE18 }\end{array}$ & LAT15 - HUN15 & LAT15 - HUN15 & $\begin{array}{l}\text { LAT15 - HUN15 - } \\
\text { SWE18 }\end{array}$ \\
\hline Portugal & HUN15 - SWE18 & HUN15 - SWE18 & HUN15 - SWE18 & HUN15 - SWE18 \\
\hline Romania & ROM15 & $\begin{array}{l}\text { HUN15 - ROM15 } \\
\text { - SWE18 }\end{array}$ & $\begin{array}{l}\text { LAT15 - HUN15 - } \\
\text { ROM15 - SWE18 }\end{array}$ & $\begin{array}{l}\text { LAT15 - HUN15 - } \\
\text { ROM15 - SWE18 }\end{array}$ \\
\hline Slovenia & LAT15 - SWE18 & LAT15 - SWE18 & LAT15 - SWE18 & $\begin{array}{l}\text { LAT15 - HUN15 - } \\
\text { SWE18 }\end{array}$ \\
\hline Slovakia & $\begin{array}{l}\text { LAT15 - HUN15 - } \\
\text { LAT18 - SWE18 }\end{array}$ & $\begin{array}{l}\text { HUN15 - LAT18 - } \\
\text { SWE18 }\end{array}$ & $\begin{array}{l}\text { HUN15 - LAT18 - } \\
\text { SWE18 }\end{array}$ & $\begin{array}{l}\text { HUN15 - LAT18 - } \\
\text { SWE18 }\end{array}$ \\
\hline Finland & $\begin{array}{l}\text { LAT15 - HUN15 - } \\
\text { SWE18 }\end{array}$ & $\begin{array}{l}\text { LAT15 - HUN15 - } \\
\text { SWE18 }\end{array}$ & $\begin{array}{l}\text { LAT15 - HUN15 - } \\
\text { SWE18 }\end{array}$ & $\begin{array}{l}\text { LAT15 - HUN15 - } \\
\text { SWE18 }\end{array}$ \\
\hline Sweden & $\begin{array}{l}\text { HUN15 - LAT17 - } \\
\text { NET17 - SWE17 }\end{array}$ & $\begin{array}{l}\text { HUN15 - SWE17 - } \\
\text { SWE18 }\end{array}$ & SWE17 & SWE18 \\
\hline UK & HUN15 - SWE18 & HUN15 - SWE18 & HUN15 - SWE18 & $\begin{array}{l}\text { DEN17 - HUN17 - } \\
\text { SWE18 }\end{array}$ \\
\hline
\end{tabular}


Table A.3: CI results and transport environmental taxes.

\begin{tabular}{|c|c|c|c|c|c|c|c|c|}
\hline & \multicolumn{2}{|c|}{2015} & \multicolumn{2}{|c|}{2016} & \multicolumn{2}{|c|}{2017} & \multicolumn{2}{|c|}{2018} \\
\hline Country & Taxes & CI & Taxes & CI & Taxes & CI & Taxes & CI \\
\hline Denmark & 74.188 & 0.949 & 76.659 & 0.922 & 78.659 & 1.000 & 78.079 & 0.777 \\
\hline Netherlands & 41.424 & 1.000 & 42.175 & 0.910 & 44.937 & 1.000 & 46.924 & 1.000 \\
\hline Finland & 33.141 & 0.791 & 37.683 & 0.610 & 39.799 & 0.730 & 40.231 & 0.685 \\
\hline Ireland & 40.040 & 0.140 & 40.403 & 0.124 & 40.006 & 0.131 & 39.258 & 0.117 \\
\hline Austria & 33.876 & 0.791 & 34.692 & 0.788 & 36.688 & 0.772 & 37.346 & 0.804 \\
\hline Malta & 24.697 & 0.113 & 25.057 & 0.112 & 26.863 & 0.116 & 27.482 & 0.118 \\
\hline Belgium & 25.433 & 0.547 & 24.985 & 0.564 & 25.712 & 0.582 & 26.458 & 0.597 \\
\hline Sweden & 20.569 & 0.877 & 21.117 & 0.937 & 20.689 & 1.000 & 20.327 & 1.000 \\
\hline UK & 23.090 & 0.415 & 20.612 & 0.403 & 19.428 & 0.409 & 19.718 & 0.472 \\
\hline Italy & 16.427 & 0.533 & 17.292 & 0.539 & 17.317 & 0.502 & 17.944 & 0.536 \\
\hline Cyprus & 13.398 & 0.108 & 13.496 & 0.108 & 14.158 & 0.108 & 14.003 & 0.108 \\
\hline Portugal & 10.823 & 0.367 & 12.101 & 0.384 & 13.332 & 0.384 & 13.944 & 0.402 \\
\hline Greece & 12.627 & 0.189 & 12.890 & 0.162 & 13.373 & 0.216 & 13.546 & 0.242 \\
\hline Germany & 12.104 & 0.524 & 12.202 & 0.543 & 12.196 & 0.537 & 12.379 & 0.547 \\
\hline Luxembourg & 12.338 & 0.485 & 11.736 & 0.465 & 11.418 & 0.484 & 11.284 & 0.486 \\
\hline Croatia & 8.757 & 0.461 & 9.347 & 0.326 & 10.375 & 0.319 & 10.127 & 0.481 \\
\hline France & 9.484 & 0.532 & 9.236 & 0.520 & 9.370 & 0.532 & 10.108 & 0.522 \\
\hline Slovenia & 8.602 & 0.469 & 8.610 & 0.396 & 9.075 & 0.492 & 9.607 & 0.540 \\
\hline Spain & 5.496 & 0.292 & 5.741 & 0.440 & 5.859 & 0.377 & 6.128 & 0.394 \\
\hline Latvia & 5.582 & 1.000 & 5.875 & 0.848 & 5.787 & 0.792 & 5.986 & 1.000 \\
\hline Hungary & 5.038 & 1.000 & 5.283 & 1.000 & 5.698 & 1.000 & 5.710 & 0.919 \\
\hline Slovakia & 3.761 & 0.884 & 3.935 & 0.927 & 4.108 & 0.893 & 4.273 & 0.912 \\
\hline Poland & 2.399 & 0.632 & 2.543 & 0.600 & 2.802 & 0.594 & 3.020 & 0.617 \\
\hline Czechia & 2.171 & 0.759 & 2.248 & 0.787 & 2.392 & 0.811 & 2.473 & 0.789 \\
\hline Bulgaria & 1.797 & 0.694 & 2.182 & 0.685 & 2.212 & 0.654 & 2.471 & 0.651 \\
\hline Lithuania & 1.086 & 0.787 & 1.165 & 0.762 & 1.210 & 0.782 & 1.371 & 0.823 \\
\hline Romania & 2.028 & 1.000 & 2.028 & 0.975 & 1.315 & 0.945 & 1.117 & 0.922 \\
\hline Estonia & 0.925 & 0.155 & 0.951 & 0.157 & 0.991 & 0.153 & 1.003 & 0.708 \\
\hline Mean & 16.118 & 0.589 & 16.509 & 0.571 & 16.992 & 0.583 & 17.226 & 0.613 \\
\hline
\end{tabular}




\section{Appendix B}

\section{BoD reverse indicators code}

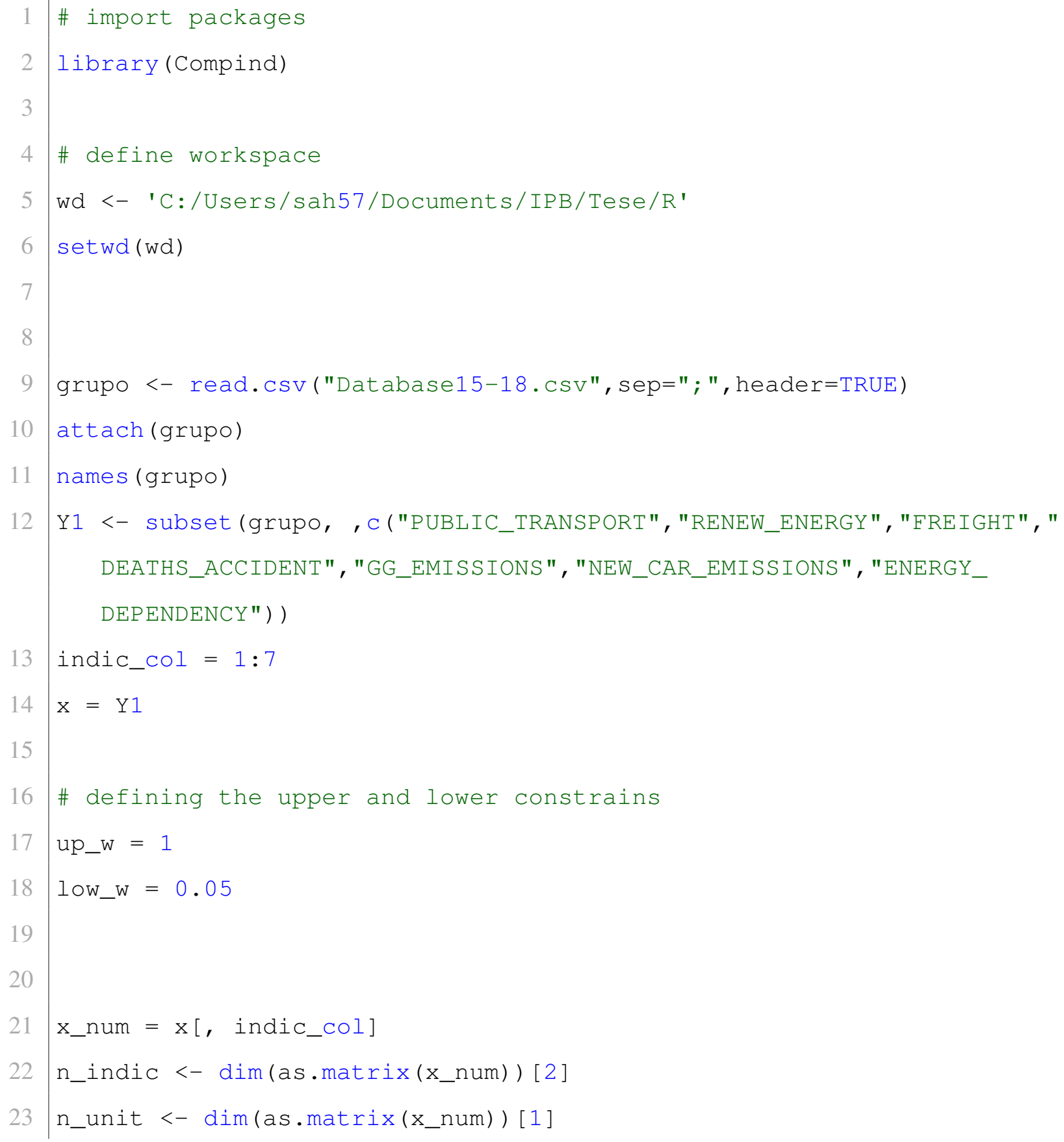




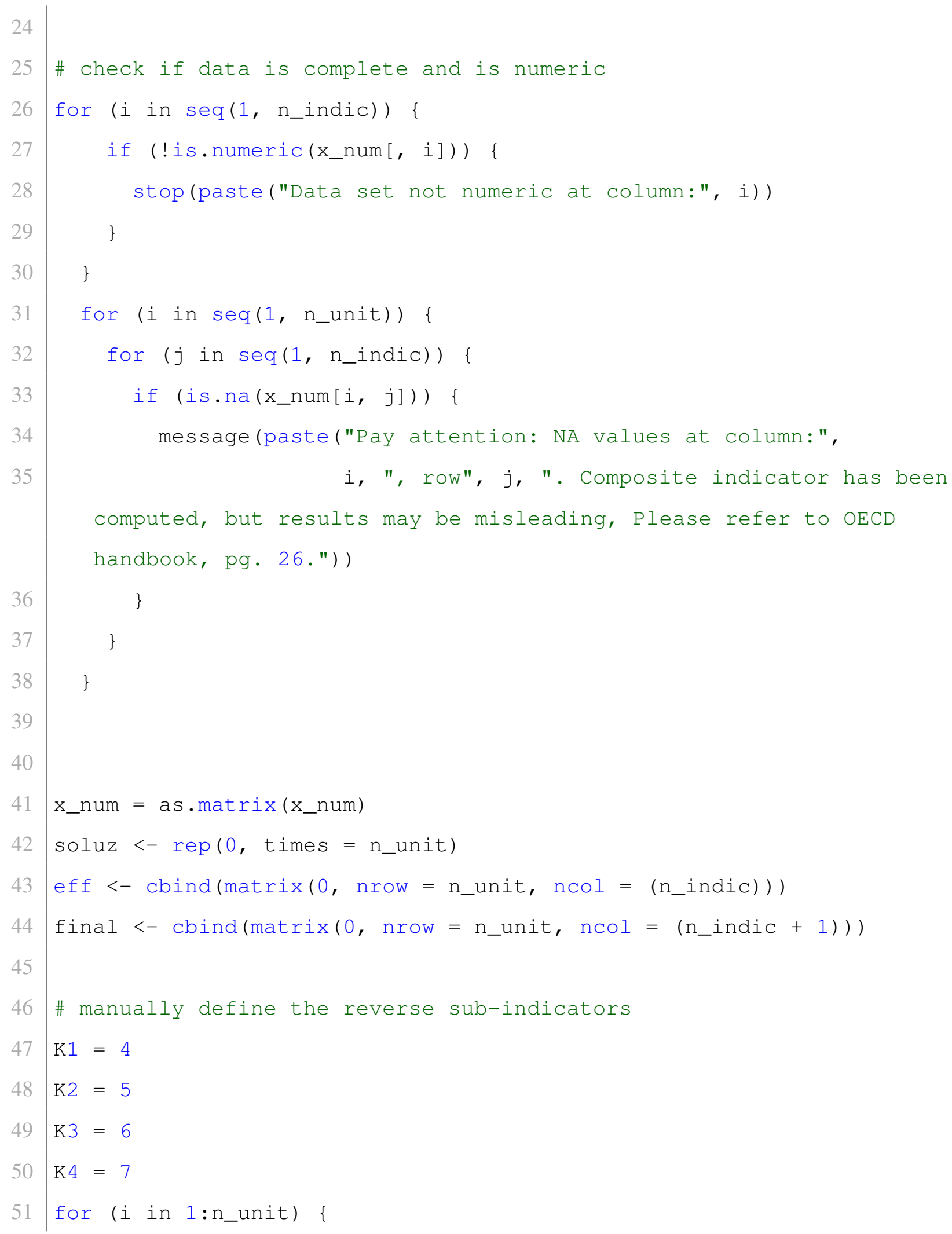

51 for (i in 1:n_unit) \{ 


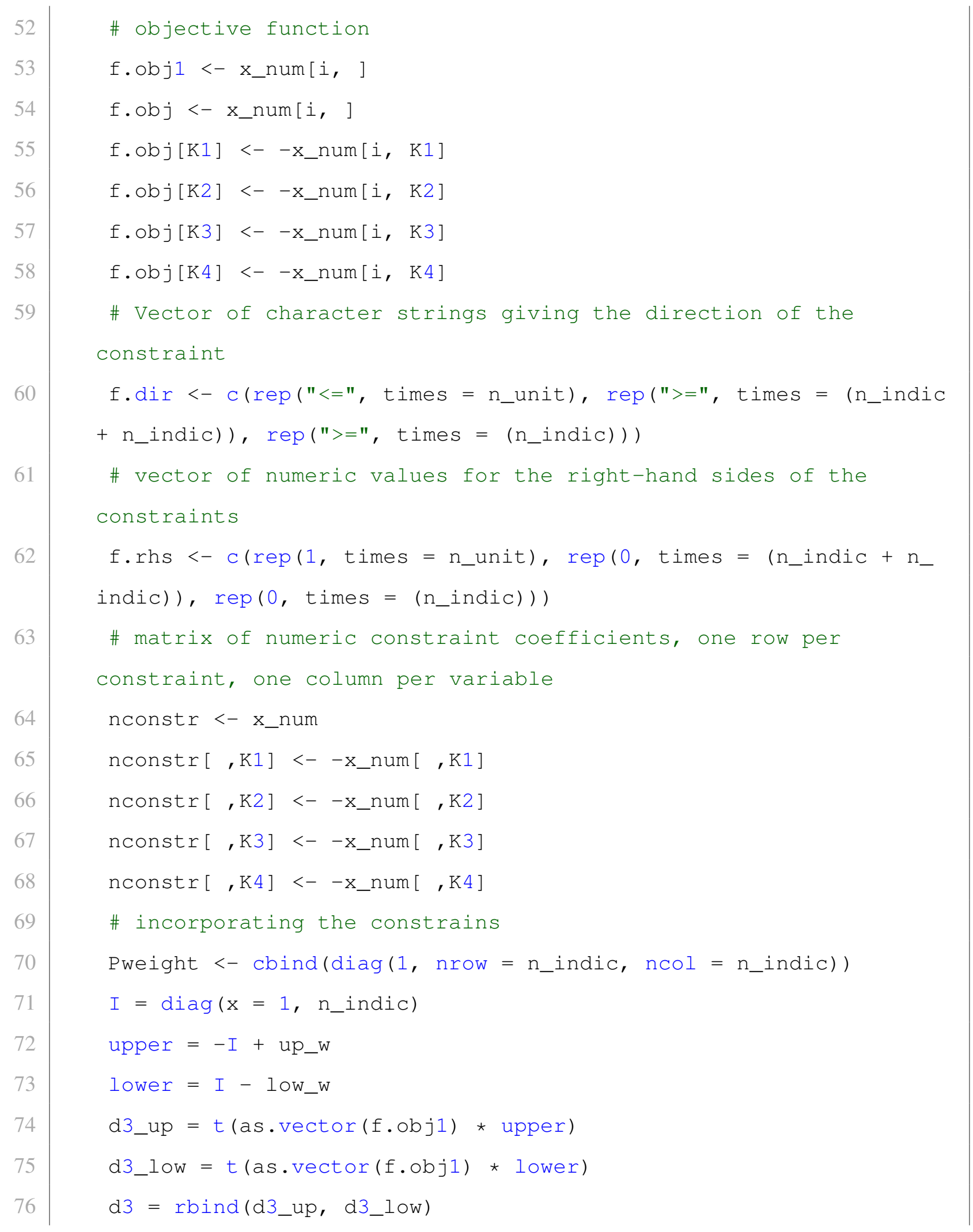




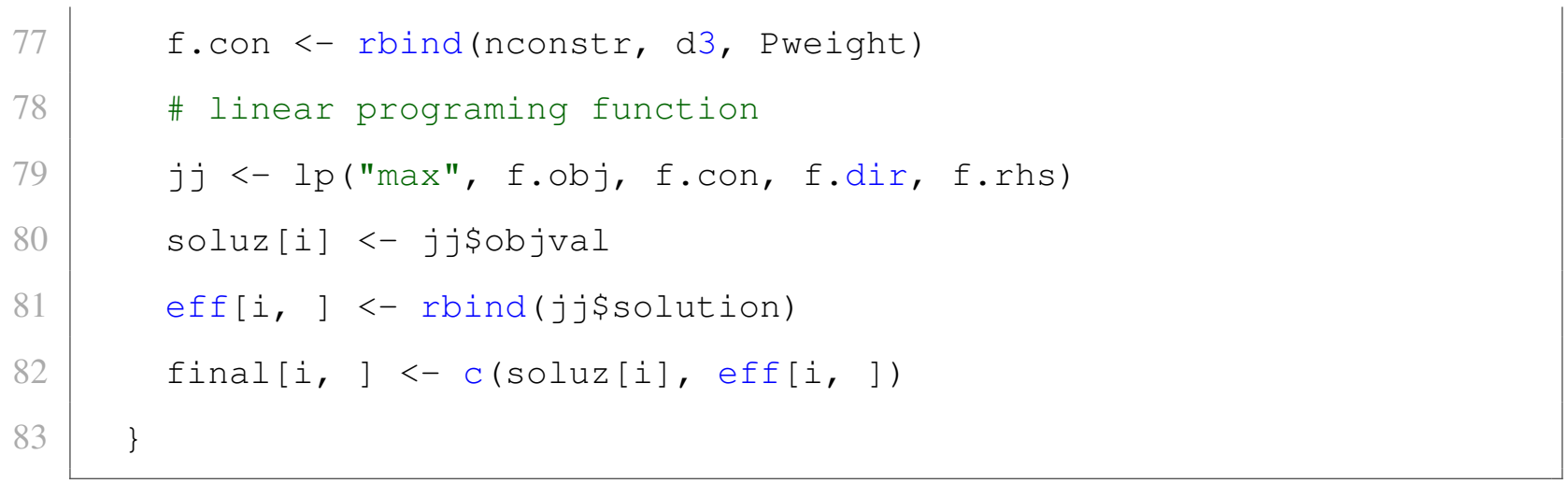

